\title{
Financial Factors and Labor Market Fluctuations
}

\author{
Yahong Zhang*
}

January 25,2015

\begin{abstract}
What are the effects of financial market imperfections on fluctuations in unemployment and vacancies for the US economy? In this paper I augment a standard monetary DSGE model with explicit financial and labor market frictions. I estimate the model using US data for the period 1984:Q1-2008:Q4 and find that the model accounts well for the cyclical behavior of unemployment and vacancies observed in the data. The financial accelerator mechanism plays an important role in amplifying the effect of the financial shock on unemployment. Overall, the financial shock contributes more than 30 per cent of the fluctuations in unemployment and vacancies in the US. I also find that the estimated degree of financial frictions is higher when financial data are included in the estimation.

JEL: classification: E32;E44; J6
\end{abstract}

Keywords: Financial frictions; Financial shocks; Unemployment; Search and matching models;

${ }^{*}$ Department of Economics, University of Western Ontario, London, Ontario, Canada N6A 5C2; E-mail: yzhang29@uwo.ca 


\section{Introduction}

The recent financial crisis has been associated with a significant rise in the unemployment rate in the US. The unemployment rate more than doubled from 4.8 percent in the beginning of the recession to peak at 10 percent in the last quarter of 2009. Given this, it seems logical and timely to evaluate the effects of financial market imperfections on the fluctuations in unemployment and vacancies in the labour market. This paper develops and estimates a quantitative macroeconomic model that incorporates both labour and financial market frictions using US time series data from 1984Q1 to 2008Q4. The objective of the paper is to explore the interaction of financial and labour market frictions, and assess quantitatively, through this interaction, how important it is to consider financial frictions and shocks when addressing labour market dynamics.

There is an important strand of literature studying the effect of financial market imperfections on unemployment. These studies usually assume that there exists some difficulties for firms to access credit and these difficulties affect firms' hiring decisions. For example, Wasmer and Weil (2004) assume that new entrepreneurs have no wealth of their own and must raise funds in an imperfect credit market before they enter the labour market to search for workers. Acemoglu (2001) studies a model in which an agent need to decide to become an entrepreneur or a worker. In order to hire workers, the entrepreneurs either borrow funds or use their own wealth. Both studies show that credit frictions increase unemployment. Recent studies have been focusing more on the effects of credit frictions on the dynamics of unemployment and vacancies. Petrosky-Nadeau (2014) assumes that firms must seek external funds to finance the costs of posting vacancies and that the credit market is subject to costly state verification frictions. He shows that the credit market frictions amplify and propagate the responses of unemployment and vacancies to productivity shocks. Monacelli, Quadrini and Trigari (2011) study a model in which firms issue debt under limited enforcement. They show that in this environment credit shocks can generate large employment fluctuations.

The abovementioned models, however, are stylized models that most of them only consider the effects of productivity shocks on unemployment. Without other frictions and other competing shocks, it is difficult to quantify the contribution of credit frictions and shocks to labour market fluctuations. DSGE (Dynamic Stochastic General Equilibium) models, in contrast, can allow for many shocks and frictions, and thus are more suitable for quantitative analysis. However, although the recent DSGE literature has shown a growing interest in the role of financial shocks and frictions in business cycle fluctuations (for example, Bernanke, Gertler and Gilchrist 1999, herein BGG; Christiano, Motto, Rostagno 2010), it has largely abstracted from modelling unemployment in models where financial factors play an important role. One exception is Christiano, Tribant and Walentin (2011) (herein, CTW). CTW introduce the BGG-type financial frictions and Montensen-Passridis search model into an otherwise standard DSGE mdoel. They estimate the model using Swedish data and show that financial shocks and frictions have important impacts on unemployment fluctuations.

This paper augments a standard DSGE model with financial and labour market frictions along the lines of CTW: The financial market frictions are modeled as in BGG. Due to information asym- 
metry, there exist financial frictions in capital acquisition, which amplify and propagate shocks to the macroeconomy (financial accelerator mechanism). The labour market frictions are modeled using a search and matching framework, and the wage setting frictions are modeled as in Gertler, Sala and Trigari (2008). As in CTW, the model economy is subject to multiple shocks, including the conventional ones such as technology and monetary policy shocks, and less conventional ones such as shocks to entrepreneurs' financial wealth and workers' bargaining power. The key differences from CTW are as follows: 1). CTW uses a small-open economy model and studies the Swedish economy; the model in this paper is a closed-economy model and it is estimated to the U.S. economy; 2). Although CTW introduce unemployment into a comprehensive monetary business cycle model, analyzing labour market dynamics is not the focus of their paper, and they stop short of providing detailed analysis of how financial frictions and shocks affect labour market outcomes. In contrast, in this paper I focus on the impact of the financial factors on labour market activities. In particular, I highlight the role of the financial accelerator mechanism in amplifying the responses in unemployment and vacancies to financial shocks, and how the interaction between financial frictions and wage setting frictions affects labour market outcomes.

In the model, financial imperfections affect unemployment and vacancies in the following way: After a negative financial shock that reduces the entrepreneurs' net worth, the worsened balancesheet position forces entrepreneurs to face a higher risk premium when borrowing external funds. Since the external financing becomes more costly, the demand for capital declines. Due to the constant returns to scale aggregate production function, it is optimal for entrepreneurs to keep a constant capital labour ratio. Thus, the demand for labour declines, leading firms to post fewer vacancies. This reduces the labour market tightness and the probability for a worker to find a job, leading fewer workers to leave the unemployment state. In this model, the financial accelerator mechanism amplifies the net worth shocks and generates large fluctuations in unemployment and vacancies even though firms' vacancy postings are not subject to financial frictions directly.

I estimate the model using US time series data from 1984Q1 to 2008Q4 - the period includes the "Great Moderation" period and the beginning of recent recession. ${ }^{1}$ The main findings of the paper are the following. First, financial wealth shocks, the shocks affecting the net worth in the entrepreneurs' sector, account for around 30 per cent of the variations of unemployment and vacancies in the long run. Historical decomposition also suggests that the financial wealth shocks contribute significantly to the two recent recessions. Second, including financial data into estimation generates a higher value for the elasticity of external finance, the key parameter capturing financial frictions, leading to a larger amplification effect from the financial accelerator. Third, compared to the "Great Inflation" period (1966Q2 to 1979Q2), I find that financial shocks are more persistent and volatile and account for a larger portion of variations in unemployment and vacancies in the U.S. in the recent period. Lastly, I find that the shocks to workers' bargaining power, a new labour market shock,

\footnotetext{
${ }^{1}$ Since 2009Q1, the nominal interest rate is at its zero lower bound. Since linear methods are used to solve and estimate the model, and the zero lower bound has not been imposed as an explicit constraint, I exclude the recent data in estimation of the model.
} 
account for a significant portion of the fluctuations in unemployment and vacancies.

The paper is organized as follows. In the next section, I describe the model, and then go on to discuss the data and estimation strategy in Section 3. In Section 4, I present the estimation results, discuss the performance of the model and quantify the sources of labour market fluctuations. In Section 5, I discuss several issues regarding the robustness of the results. Finally, in Section 6, I offer some concluding remarks.

\section{The Model}

In this section I describe the model economy. I consider an economy populated by a representative household, retailers, entrepreneurs, capital producers and employment agencies. Each member in the household consumes, holds nominal bonds, and decides whether to provide labor inelastically to employment agencies. Employment agencies hire workers from a frictional labor market, which is subject to an aggregate matching function. The nominal wage paid to an individual worker is determined by Nash bargaining. However, in each period an employment agency has a fixed probability that it may renegotiate the wage. Employment agencies make hiring decisions and supply labor services to entrepreneurs at the price of marginal productivity of the labor services. Entrepreneurs also acquire capital from capital producers. Since entrepreneurs have to obtain external finance for their capital purchasing, they are subject to financial market frictions. Retailers purchase the wholesale goods produced by entrepreneurs and differentiate at no cost and sell them to final good producers, who aggregate differentiated goods into a homogeneous good and supply it to the representative household.

\subsection{Households}

There is a representative household with a continuum of members of measure one. The number of family members currently employed is $n_{t}$. The employed family members earn nominal wage $w_{t}^{n}$. The unemployed members receive unemployment benefit $\bar{b}_{t}$. Each member has the following period utility function

$$
u\left(c_{t}\right)=e_{t} \log \left(c_{t}-h c_{t-1}\right),
$$

where $c_{t}$ is consumption of final goods in period $t$, and $h$ is the degree of habit persistence in consumption. A preference shock $e_{t}$ follows an $\mathrm{AR}(1)$ process,

$$
\log e_{t}=\rho_{e} \log e_{t-1}+\epsilon_{t}^{e}, \quad \epsilon_{t}^{e} \sim \text { i.i.d. } N\left(0, \sigma_{\epsilon^{e}}^{2}\right)
$$

Following Andolfatto (1996) and Merz (1995), I assume that family members are perfectly insured against the risk of being unemployed, thus consumption is the same for each family member. The representative household maximizes the lifetime utility

$$
E_{0} \sum_{t=0}^{\infty} \beta^{t} u\left(c_{t}\right) .
$$


The wage income from the employed family members is $w_{t}^{n} n_{t}$, where $w_{t}^{n}$ is determined by Nash bargaining between employment agencies and workers and $n_{t}$ is determined by a search and match process in the labor market. The household also earns income from owning equity in retailers $\Pi_{t}$, pays tax $T_{t}$ and saves by holding a one-period riskless nominal bond $B_{t}$. Assuming that the aggregate price is $p_{t}$, the representative household is subject to the following budget constraint

$$
c_{t}=\frac{w_{t}^{n}}{p_{t}} n_{t}+\bar{b}_{t}\left(1-n_{t}\right)+\Pi_{t}-T_{t}-\frac{B_{t}-r_{t-1}^{n} B_{t-1}}{p_{t}},
$$

where $r_{t-1}^{n}$ is the nominal rate of return on the riskless bond.

The household maximizes its expected lifetime utility equation (1) subject to equation (2). The first-order condition for consumption is

$$
\lambda_{t}=\frac{e_{t}}{c_{t}-h c_{t-1}}-\beta h E_{t}\left[\frac{e_{t+1}}{c_{t+1}-h c_{t}}\right]
$$

and

$$
\lambda_{t}=r_{t}^{n} \beta E_{t}\left[\frac{\lambda_{t+1} p_{t}}{p_{t+1}}\right],
$$

where $\lambda_{t}$ is the marginal utility of consumption.

\subsection{Wholesale Firms (Entrepreneurs)}

Following BGG, firms (entrepreneurs) are risk-neutral, and manage the production of wholesale goods. The production function for entrepreneur $j$ is given by

$$
y_{t}(j)=f\left(k_{t}(j), l_{t}(j)\right)=z_{t} \omega_{t}(j)\left(k_{t}(j)\right)^{\alpha}\left(l_{t}(j)\right)^{1-\alpha}
$$

where $k_{t}(j)$ is the capital purchased from the capital producers at the end of period $t-1$, and $l_{t}(j)$ is the labour services purchased at period $t$ from the employment agencies. Both capital producers and employment agencies operate in competitive markets, and the prices of capital and labour services are $q_{t}$ and $p_{t}^{l}$, respectively. Production is subject to two type of shocks: $\omega_{t}$ is the idiosyncratic shock, which is private information to the entrepreneur and is i.i.d across entrepreneurs and time, with mean $E\left[\omega_{t}(j)\right]=1 ; z_{t}$ is an exogenous aggregate technology shock that is common to all entrepreneurs, and it follows

$$
\log z_{t}=\rho_{z} \log z_{t-1}+\epsilon_{t}^{z}, \quad \epsilon_{t}^{z} \sim \text { i.i.d. } N\left(0, \sigma_{\epsilon^{z}}^{2}\right)
$$

At the end of each period, entrepreneur $j$ needs to decide how much capital she needs to purchase. The capital $k_{t+1}(j)$, purchased at the end of period $t$ and used in period $t+1$, is partly financed from the entrepreneur's net worth at the end of period $t, N_{t}(j)$, and partly from issuing nominal debt, 
$B_{t}(j)$

$$
q_{t} k_{t+1}(j)=N_{t}(j)+\frac{B_{t}(j)}{p_{t}}
$$

where $q_{t}$ is the price of capital relative to the aggregate price $p_{t}$. Note that the debt contract is in nominal terms. That is, entrepreneurs sign a debt contract that specifies a nominal interest rate. To ensure that entrepreneurs will never accumulate enough funds to finance capital acquisitions entirely out of net worth, following BGG, I assume that they have finite lives. The probability that an entrepreneur survives until the next period is $\eta^{e}$, and the exiting entrepreneurs will be replaced by the newly born entrepreneurs, thus the fraction of agents who are entrepreneurs is constant.

The financial market imperfections in the model are as follows: because the idiosyncratic shock $\omega_{t}(j)$ is private information for the borrowers (entrepreneurs), there exists information asymmetry between borrowers and lenders (financial intermediaries). Due to costly state verification, lenders have to pay an auditing cost to observe the output of the borrowers. As suggested in BGG, the optimal contract is a standard debt contract with costly bankruptcy. That is, if the entrepreneur does not default, the lender receives a fixed payment independent of $\omega_{t}(j)$ but contingent upon the aggregate state; if the entrepreneur defaults, the lender audits and seizes the realized return net of monitoring costs. Under this contract, external funds are more costly than internal funds. The risk premium associated with external funds, $s($.$) , is defined as the ratio of the entrepreneur's cost of$ external funds to the cost of internal funds

$$
s_{t}=\frac{E_{t} r_{t+1}^{k}}{E_{t}\left[r_{t}^{n} \frac{p_{t}}{p_{t+1}}\right]},
$$

where $E_{t} r_{t+1}^{k}$ is the expected rate of return of capital (defined in the next section), which is equal to the expected cost of external funds in equilibrium, and $E_{t}\left[r_{t}^{n} \frac{p_{t}}{p_{t+1}}\right]$ is the cost of internal funds. BGG shows that $s($.$) , depends on the entrepreneur's balance sheet position and it can be characterized by$

$$
s_{t}=s\left(\frac{q_{t} k_{t+1}(j)}{N_{t}(j)}\right)
$$

where $s^{\prime}()>$.0 and $s(1)=1 .^{2}$ Equation (5) expresses that the external finance premium increases with leverage, or decreases with the share of entrepreneurs' capital investment that is financed by the entrepreneur's own net worth. When entrepreneurs rely more on external financing, the riskiness of loans increases. Lenders' expected loss increases and thus they charge a higher risk premium.

BGG has also shown that given the assumptions on the production function and loan contract, the capital acquisition are proportional to the net worth of the entrepreneur. Thus the risk premium is the same to all entrepreneurs, regardless of their net worth, and equation (5) can be written in the

\footnotetext{
${ }^{2}$ See Appendix A in BGG for details.
} 
aggregation form

$$
s_{t}=s\left(\frac{q_{t} k_{t+1}}{N_{t}}\right)
$$

where $k_{t+1}=\int k_{t+1}(j) d j$ and $N_{t}=\int N_{t}(j) d j$.

\subsubsection{Entrepreneurs' net worth, demands for capital and labour}

At the end of the period $t$, the entrepreneur $j$ 's net worth is

$$
N_{t}(j)=p_{t}^{w} y_{t}(j)+q_{t}(1-\delta) k_{t}(j)-p_{t}^{l} l_{t}(j)-\frac{r_{t-1}^{n} s_{t-1}}{1+\pi_{t}} b_{t-1}(j)
$$

where $p_{t}^{w}$ is the relative price of wholesale goods, and $b_{t}$ is the real debt $\left(b_{t}=B_{t} / P_{t}\right)$. At the end of period $t$, on one hand, entrepreneur $j$ ' production revenue is $p_{t}^{w} y_{t}(j)$, and the value for the un-depreciated capital is $q_{t}(1-\delta) k_{t}(j)$. On the other hand, the labour costs are $p_{t}^{l} l_{t}(j)$, and the outstanding liabilities are $\frac{r_{t-1}^{n} s_{t-1}}{1+\pi_{t}} b_{t-1}(j)$. Using the constant returns to scale production function assumption and equation (3), the net worth for entrepreneur $j$ can be further expressed as

$$
\begin{aligned}
N_{t}(j) & =\frac{\left[p_{t}^{w} \alpha \frac{y_{t}(j)}{k_{t}(j)}+q_{t}(1-\delta)\right]}{q_{t-1}} q_{t-1} k_{t}(j)-\frac{r_{t-1}^{n} s_{t-1}}{1+\pi_{t}}\left[q_{t-1} k_{t}(j)-N_{t-1}(j)\right] \\
& =r_{t}^{k} q_{t-1} k_{t}-\frac{r_{t-1}^{n} s_{t-1}}{1+\pi_{t}}\left[q_{t-1} k_{t}(j)-N_{t-1}(j)\right]
\end{aligned}
$$

where $r_{t}^{k}=\frac{\left[p_{t}^{w} \alpha \frac{y_{t}(j)}{k_{t}(j)}+q_{t}(1-\delta)\right]}{q_{t-1}}$, the realized return of capital. Equation (8) is essentially the law of motion for the net worth of an individual entrepreneur.

Entrepreneur $j$ 's demands for capital and labour can be characterized by

$$
\frac{E_{t}\left[p_{t+1}^{w} \frac{\partial y_{t+1}(j)}{\partial k_{t+1}(j)}+q_{t+1}(1-\delta)\right]}{q_{t}}=E_{t}\left[\frac{r_{t}^{n} s_{t}}{1+\pi_{t+1}}\right] .
$$

and

$$
p_{t}^{w} \frac{\partial f_{t}(j)}{\partial l_{t}(j)}=p_{t}^{l}
$$

respectively. Equation (10) describes the capital demand for the entrepreneur $j$. The left hand side of the equation is the expected return of capital, which depends on the marginal productivity of capital $p_{t+1}^{w} \frac{\partial y_{t+1}(j)}{\partial k_{t+1}(j)}$ and the capital gain $\frac{q_{t+1}(1-\delta)}{q_{t}}$. The right hand of the equation is the expected cost of external funds, which is a product of risk premium $s_{t}$ and the expected cost of internal funds $\frac{r_{t}^{n}}{1+\pi_{t+1}}$.

Equation (11) simply states in the equilibrium the price for labor service $p_{t}^{l}$ is equal to its marginal productivity. 


\subsubsection{Aggregation}

In this section I characterize the key equations that describe the aggregate behavior for the entrepreneurial sector: equations for the aggregate demand curves for labour and capital, the equation for the aggregate stock of entrepreneurial net worth. ${ }^{3}$

Since production is constant returns to scale, aggregate production is

$$
y_{t}=\int y_{t}(j) d j=k_{t}^{\alpha}\left(z_{t} l_{t}\right)^{1-\alpha}
$$

where $y_{t}=\int y_{t}(j) d j$ and $l_{t}=\int l_{t}(j) d j$. Aggregating over equation (11) and equation (10) yields the following aggregate labour and capital demand equations

$$
p_{t}^{w}(1-\alpha) \frac{y_{t}}{l_{t}}=p_{t}^{l}
$$

and

$$
\frac{E_{t}\left[p_{t+1}^{w} \frac{\partial y_{t+1}}{\partial k_{t+1}}+q_{t+1}(1-\delta)\right]}{q_{t}}=E_{t}\left[\frac{r_{t}^{n} s_{t}}{1+\pi_{t+1}}\right] .
$$

The expected return of capital is defined as

$$
E_{t} r_{t+1}^{k}=\frac{E_{t}\left[p_{t+1}^{w} \alpha \frac{y_{t+1}}{k_{t+1}}+q_{t+1}(1-\delta)\right]}{q_{t}} .
$$

The aggregate net worth consists of two components, the net worth for the surviving entrepreneurs (by aggregating over equation 8 ) and $W_{t}^{e}$, which is a transfer to ensure the new arrivals to have some funds to at least obtain some amount of loans:

$$
N_{t}=\gamma_{t} \eta^{e}\left(r_{t}^{k} q_{t-1} k_{t}-\frac{r_{t-1}^{n} s_{t-1}}{1+\pi_{t}}\left(q_{t-1} k_{t}-N_{t-1}\right)\right)+W_{t}^{e}
$$

Following Christiano, Motto and Rostagno (2010), I also assume that there is a financial wealth shock, an exogenous shock to the survival probability of entrepreneurs, $\gamma_{t}$, which follows an AR(1) process:

$$
\log \gamma_{t}=\rho_{\gamma} \log \gamma_{t-1}+\epsilon_{t}^{\gamma}, \quad \epsilon_{t}^{\gamma} \sim \text { i.i.d. } N\left(0, \sigma_{\epsilon^{\gamma}}^{2}\right) .
$$

The reason why the shock on the survival probability of entrepreneurs has effects on their financial wealth is as follows: in the model, the number of entrepreneurs exiting is balanced by the number that enter. Since those who exit usually have more net worth than those who enter, when a positive shock occurs, the aggregate net worth of entrepreneurs increases.

\footnotetext{
${ }^{3}$ See on line Appendix at https://sites.google.com/site/yahongzhangwebsite/home/research for a more detailed derivation for this section's equations.
} 
Entrepreneurs going out of business will consume their residual equity,

$$
c_{t}^{e}=\left(1-\gamma_{t} \eta^{e}\right)\left(r_{t}^{k} q_{t-1} k_{t}-\frac{r_{t-1}^{n} s_{t-1}}{1+\pi_{t}}\left(q_{t-1} k_{t}-N_{t}\right)\right)
$$

where $c_{t}^{e}$ is the aggregate consumption of the entrepreneurs who exit in period $t$.

\subsection{Employment Agencies}

Following CTW, I assume that the key labour market activities-vacancy postings, wage bargainingare all carried out by employment agencies instead of entrepreneurs themselves. ${ }^{4}$ I assume that entrepreneurs obtain labor services supplied by employment agencies in a competitive labor market. Each employment agency $i$ supplies labor services $n_{t}(i)$. The labor market is modeled using a search-match framework. The employment agencies make vacancy posting decisions and bargain with workers over nominal wages. I follow Gertler and Trigari (2009) and Gertler, Sala and Trigari (2008) assuming a staggered multiple period wage contracting.

In the next subsections, I describe the matching function, employment agencies' and workers' problem, and wage dynamics under the staggered Nash bargaining mechanism.

\subsubsection{Unemployment, Vacancies and Matching}

At the beginning of period $t$, employment agency $i$ posts $v_{t}(i)$ vacancies in order to attract new workers and employs $n_{t}(i)$ workers. The total number of vacancies and employed workers are $v_{t}=\int v_{t}(i) d i$ and $n_{t}=\int n_{t}(i) d i$. The number of unemployed workers at the beginning of period $t$ is

$$
u_{t}=1-n_{t} .
$$

The number of new hires or "matches", $m_{t}$, is governed by a standard Cobb-Douglas aggregate matching technology

$$
m_{t}=\sigma_{m} u_{t}^{\sigma} v_{t}^{1-\sigma}
$$

where $\sigma_{m}$ is a parameter governing the matching efficiency. The probability a firm fills a vacancy in period $t, q_{t}^{l}$, is given by

$$
q_{t}^{l}=\frac{m_{t}}{v_{t}}
$$

Similarly, the probability that a searching worker finds a job, $s_{t}^{l}$, is given by

$$
s_{t}^{l}=\frac{m_{t}}{u_{t}} .
$$

Both firms and workers take $q_{t}^{l}$ and $s_{t}^{l}$ as given. In each period, a fraction $1-\rho$ of existing workforce $n_{t}$ exogenously separate from the firms. I assume that it takes one period for the newly formed

\footnotetext{
${ }^{4}$ Alternatively, we can assume that entrepreneurs do their own job search. However, that would significantly complicate the aggregation given that the entrepreneurs already face the financial market frictions.
} 
matches to be productive. Thus, the total labor force is the sum of the number of surviving workers and the new matches:

$$
n_{t+1}=\rho n_{t}+m_{t}
$$

\subsubsection{Employment Agencies’ Problem}

To maximize comparability with the rest of the model, I assume that there are many employment agencies that supply labor services at a competitive price $p_{t}^{l}$. These agencies combine labor supplied by households into homogeneous labor services $n_{t}=\int n_{t}(i) d i$ and supply them to entrepreneurs. This leaves the equilibrium conditions associated the production of wholesale goods unaffected even though the labour market is frictional. I define the hiring rate, $x_{t}(i)$, as the ratio of new hires, $q_{t}^{l} v_{t}(i)$, to the existing workforce, $n_{t}(i)$ :

$$
x_{t}(i)=\frac{q_{t}^{l} v_{t}(i)}{n_{t}(i)}
$$

Due to the law of large numbers the employment agency knows the likelihood $q_{t}^{l}$ that each vacancy will be filled. The hiring rate is thus the employment agency's control variable. The total labour force can be also written as

$$
\left.n_{t+1}=\int n_{t+1}(i) d i=\int\left(\rho n_{t}(i)+x_{t}(i)\right) n_{t}(i)\right) d i
$$

which gives

$$
m_{t}=\int x_{t}(i) n_{t}(i) d i
$$

The value of the employment agency $F_{t}(i)$ is

$$
F_{t}(i)=p_{t}^{l} n_{t}(i)-\frac{w_{t}^{n}(i)}{p_{t}} n_{t}(i)-\frac{\kappa}{2} x_{t}(i)^{2} n_{t}(i)+\beta E_{t} \Lambda_{t, t+1} F_{t+1}(i),
$$

where $\frac{\kappa}{2} x_{t}(i)^{2} n_{t}(i)$ is the quadratic costs of adjusting employment, and $\beta E_{t} \Lambda_{t, t+1}$ is the employment agency's discount rate with $\Lambda_{t, t+1}=c_{t} / c_{t+1}$. At any time, the employment agency chooses the hiring rate $x_{t}(i)$ to maximize $F_{t}(i)$, given the existing employment stock, $n_{t}(i)$ the probability of filling a vacancy, $q_{t}^{l}$, and the current and expected path of nominal wages $w_{t}^{n}(i) . J_{t}(i)$, the value to the employment agency of adding another worker at time $t$, can be obtained by differentiating $F_{t}(i)$ with respect to $n_{t}(i)$ :

$$
J_{t}(i)=p_{t}^{l}-\frac{w_{t}^{n}(i)}{p_{t}}-\frac{\kappa}{2} x_{t}(i)^{2}+\left(\rho+x_{t}(i)\right) \beta E_{t} \Lambda_{t, t+1} J_{t+1}(i) .
$$

The first order condition for vacancy posting equates the marginal cost of adding a worker with the discounted marginal benefit:

$$
\kappa x_{t}(i)=\beta E_{t} \Lambda_{t, t+1} J_{t+1}(i)
$$


Substituting equation (18) into equation (17):

$$
J_{t}(i)=p_{t}^{l}-\frac{w_{t}^{n}(i)}{p_{t}}+\frac{\kappa}{2} x_{t}(i)^{2}+\rho \beta E_{t} \Lambda_{t, t+1} J_{t+1}(i) .
$$

It can be shown that the value of the firm is linear in its employment level,

$$
F_{t}(i)=J_{t}(i) n_{t}(i)
$$

and the hiring rate $x_{t}(i)$ can be further expressed as

$$
\kappa x_{t}(i)=\beta E_{t} \Lambda_{t, t+1}\left(p_{t}^{l}-\frac{w_{t}^{n}(i)}{p_{t}}+\frac{\kappa}{2} x_{t}(i)^{2}+\rho \kappa x_{t+1}(i)\right) .
$$

Thus, the hiring rate depends on a discounted steam of the employment agency's expected future surpluses from the marginal worker, and depends only on wage $w_{t}^{n}(i)$, regardless the employment size. The average economy-wide nominal wage rate and average hiring rate are thus defined as

$$
w_{t}^{n}=\int w_{t}^{n}(i) d G\left(w_{t}^{n}\right)
$$

and

$$
x_{t}=\int x_{t}(i) d G\left(w_{t}^{n}\right)
$$

where $G\left(w_{t}^{n}\right)$ is the cumulative distribution function of wages.

\subsubsection{Workers' Problem}

The value to a worker of employment at agency $i, V_{t}(i)$, is,

$$
V_{t}(i)=\frac{w_{t}^{n}(i)}{p_{t}}+\beta E_{t} \Lambda_{t, t+1}\left[\rho V_{t+1}(i)+(1-\rho) U_{t+1}\right]
$$

The average value of employment on being a new worker at time $t, V_{t}$, is

$$
V_{t}=\int V_{t}(i) \frac{x_{t}(i) n_{t}(i)}{x_{t} n_{t}} d i
$$

The value of unemployment, $U_{t}$, depends on the unemployment benefit $\bar{b}$ and the probability of being employed versus unemployed next period:

$$
U_{t}=\bar{b}+\beta E_{t} \Lambda_{t, t+1}\left[s_{t}^{l} V_{t+1}+\left(1-s_{t}^{l}\right) U_{t+1}\right]
$$

Denote the workers' surplus at firm $i$ as $H_{t}(i)$, and it is given by:

$$
H_{t}(i)=V_{t}(i)-U_{t}
$$


and further denote the average workers' surplus as $H_{t}$, and it is given by:

$$
H_{t}=V_{t}-U_{t}
$$

It follows that $H_{t}(i)$ can be further expressed as

$$
H_{t}(i)=w_{t}(i)-\bar{b}+\beta E_{t} \Lambda_{t, t+1}\left[\rho H_{t+1}(i)-s_{t}^{l} H_{t+1}\right]
$$

\subsubsection{Nash Bargaining and Wage Dynamics}

Every period, each employment agency has a fixed probability $1-\lambda$ that it may renegotiate the nominal wage $w_{t}^{n}$. At the beginning of period $t$, for employment agencies that are allowed to renegotiate the wage, they negotiate with the existing workforce, including the newly hires. Due to the value of the firm is linear in its employment level, all workers are the same at the margin, and the wage negotiation is between the firm and the marginal worker. For employment agencies that are not allowed to renegotiate the wage, all existing and newly hired workers receive the wage paid in the previous period adjusted by steady-state inflation. ${ }^{5}$ Thus, the renegotiating employment agency $i$ solves the following problem:

$$
\max H_{t}(i)^{\eta_{t}} J_{t}(i)^{1-\eta_{t}}
$$

s.t.

$$
\begin{aligned}
w_{t}^{n}(i) & =w_{t}^{n *} \text { with probability } 1-\lambda \\
& =w_{t-1}^{n} \pi \text { with probability } \lambda
\end{aligned}
$$

where $\pi$ is the steady-state inflation rate. Following Gertler, Sala and Trigari (2008), I assume

$$
\eta_{t}=\eta \varepsilon_{t}
$$

where $\varepsilon_{t}$ is a bargaining power shock, which follows an $\operatorname{AR}(1)$ process:

$$
\log \varepsilon_{t}=\rho_{\omega} \log \varepsilon_{t-1}+\epsilon_{t}^{\varepsilon}, \quad \epsilon_{t}^{\varepsilon_{t}} \sim \text { i.i.d. } N\left(0, \sigma_{\epsilon^{\varepsilon_{t}}}^{2}\right) .
$$

The first order condition for the Nash bargaining solution is given by

$$
\eta_{t} \frac{\partial H_{t}(i)}{\partial w_{t}^{n}(i)} J_{t}(i)=\left(1-\eta_{t}\right) \frac{\partial J_{t}(i)}{\partial w_{t}^{n}(i)} H_{t}(i)
$$

\footnotetext{
${ }^{5}$ This simple Poisson adjustment process implies that it is not necessary to keep track of individual firms' wage histories, which simplifies aggregation. Given constant returns, all sets of renegotiating employment agencies and workers at time $t$ face the same problem, and set the same nominal wage, $w_{t}^{n *}$.
} 
with $\frac{\partial H_{t}(i)}{\partial w_{t}^{n}(i)}=1 / p_{t}+\rho \lambda \pi \beta E_{t} \Lambda_{t, t+1} \frac{\partial H_{t+1}(i)}{\partial w_{t+1}^{n}(i)}$, and $\frac{\partial J_{t}(i)}{\partial w_{t}^{n}(i)}=-1 / p_{t}+\rho \lambda \pi \beta E_{t} \Lambda_{t, t+1} \frac{\partial J_{t+1}(i)}{\partial w_{t+1}^{n}(i)}$. Let $\epsilon_{t}=p_{t} \frac{\partial H_{t}(i)}{\partial w_{t}^{n}(i)}$ and $\mu_{t}=-p_{t} \frac{\partial J_{t}(i)}{\partial w_{t}^{n}(i)}$ and we can show that

$$
\epsilon_{t}=\mu_{t}
$$

Given this, the first order condition for wages (equation 23) becomes the conventional sharing rule: ${ }^{6}$

$$
\eta_{t} J_{t}(i)=\left(1-\eta_{t}\right) H_{t}(i)
$$

However, due to the staggered wage contracting, $J_{t}(i)$ and $H_{t}(i)$ are different from the ones that would be obtained from period-by-period Nash bargaining. Further for the renegotiating firm $i$ we can write

$$
\begin{gathered}
J_{t}(i)=E_{t} \sum_{s=0}^{\infty}(\rho \beta)^{s} \Lambda_{t, t+s}\left[p_{t+s}^{l}+\frac{\kappa}{2} x_{t+s}^{2}\right]-W_{t}(i) \\
H_{t}(i)=W_{t}(i)-E_{t} \sum_{s=0}^{\infty}(\rho \beta)^{s} \Lambda_{t, t+s}\left[b+s_{t+s+1} \beta \Lambda_{t+s, t+s+1} H_{t+s+1}\right]
\end{gathered}
$$

where $W_{t}(i)$ denotes the sum of expected future wage payments over the existing contract and subsequent contracts, where

$$
\Delta_{t}=E_{t} \sum_{s=0}^{\infty}(\rho \beta \lambda)^{s} \Lambda_{t, t+s} \frac{p_{t}}{p_{t+s}} \pi^{s} .
$$

After substituting equations (25) and (26) into the Nash bargaining first-order condition

$$
\eta_{t} J_{t}(i)=\left(1-\eta_{t}\right) H_{t}(i)
$$

the equation for the contract wage in real term $w_{t}(i)$ is

$$
\begin{aligned}
\Delta_{t} w_{t}(i)= & \eta_{t}\left(p_{t}+\frac{\kappa}{2} x_{t}^{2}(i)\right)+\left(1-\eta_{t}\right)\left(\bar{b}+s_{t+1} \beta \Lambda_{t, t+1} H_{t+s+1}\right) \\
& +\lambda \rho \beta E_{t} \Lambda_{t, t+1} \Delta_{t+1} w_{t+1}(i)
\end{aligned}
$$

The first two terms of equation (27) are conventional components for Nash bargaining solutions for wages: the first term is the worker's contribution to the match and the second is the workers' opportunity cost. The third term is from the staggered multi-period contracting. Following Gertler

${ }^{6}$ This result is different from Gertler and Trigari (2009). They suggest $\mu_{t}>\epsilon_{t}$. This leads to horizon effect in their paper, although they find that this effect is not qualitatively significant. In their paper, $\frac{\partial J_{t}(i)}{\partial w_{t}^{n}(i)}=-1 / p_{t}+$ $\left(\rho+x_{t}(i)\right) \lambda \pi \beta E_{t} \Lambda_{t, t+1} \frac{\partial J_{t+1}(i)}{\partial w_{t+1}^{n}(i)}$, which is computed by taking derivatives of equation (17). However, once taking account the first order condition for vacancy posting, $J_{t}(i)$ can be expressed as $J_{t}(i)=p_{t}^{l}-\frac{w_{t}^{n}(i)}{p_{t}}+\frac{\kappa}{2} x_{t}(i)^{2}+$ $\rho \beta E_{t} \Lambda_{t, t+1} J_{t+1}(i)$. In this case, $\frac{\partial J_{t}(i)}{\partial w_{t}^{n}(i)}=-1 / p_{t}+\rho \lambda \pi \beta E_{t} \Lambda_{t, t+1} \frac{\partial J_{t+1}(i)}{\partial w_{t+1}^{n}(i)}$, and $\epsilon_{t}=\mu_{t}$. 
and Trigari (2009), I define a target wage $w_{t}^{\operatorname{tar}}(i)$ as the sum of the first two terms:

$$
w_{t}^{t a r}(i)=\eta_{t}\left(p_{t}+\frac{\kappa}{2} x_{t}^{2}(i)\right)+\left(1-\eta_{t}\right)\left(\bar{b}+s_{t}^{l} \beta \Lambda_{t, t+1} H_{t+s+1}\right) .
$$

The target wage is computed as the wage that would arise under period-by-period Nash bargaining for the employment agency $i$, taking as given that all other employment agencies and workers operates on multi-period wage contracts. It is different from the conventional Nash bargaining wage $w_{t}^{\text {flex }}$, which would arise if all employment agencies and workers were operating on period-byperiod wage contract:

$$
w_{t}^{f l e x}=\eta_{t}\left(p_{t}^{l}+\frac{\kappa}{2} x_{t}^{2}+s_{t}^{l} \kappa x_{t}\right)+\left(1-\eta_{t}\right) \bar{b}
$$

The target wage can be rewritten as

$$
\begin{aligned}
w_{t}^{\text {tar }}(i)= & \eta_{t}\left(p_{t}^{l}+\frac{\kappa}{2} x_{t}^{2}+\kappa s_{t}^{l} x_{t}\right)+\left(1-\eta_{t}\right) \bar{b} \\
& +\eta_{t}\left[\frac{\kappa}{2}\left(x_{t}^{2}(i)-x_{t}^{2}\right)+\kappa s_{t+1}^{l}\left(x_{t}(i)-x_{t}\right)\right] \\
& +\left(1-\eta_{t}\right) E_{t} s_{t+1}^{l} \beta \Lambda_{t, t+1} \lambda \pi \frac{p_{t}}{p_{t+1}} \Delta_{t+1}\left(w_{t}-w_{t}(i)\right),
\end{aligned}
$$

where the first term is $w_{t}^{f l e x}$ and $w_{t}$ is the aggregate real wage, which is defined below. As suggested in Gertler and Trigari (2009), equation (28) reflects the impact of spillovers of economy-wide average wages on the individual bargaining wage between the employment agency and worker. When $w_{t}$ exceeds $w_{t}(i)$, everything else equal, it suggests workers' outside options are good. This will raise the target wage. The reverse happens if $w_{t}$ is below $w_{t}(i)$. The stickiness in the aggregate wage affects the individual wage bargain by this type of spillover, adding more inertia to the individual wages. $^{7}$

\subsection{Capital Producers}

Capital production is assumed to be subject to an investment-specific shock, $\tau_{t}$. Capital producers purchase the final goods from retailers as investment goods, $i_{t}$, and produce efficient investment goods, $\tau_{t} i_{t}$. I assume that capital producers face capital adjustment $\operatorname{costs} \frac{\xi}{2}\left(\frac{i_{t}}{k_{t}}-\delta\right)^{2}$. The production of capital stock yields the following time-t profit function

$$
\Pi_{t}^{i}=q_{t} i_{t} \tau_{t}-\frac{\xi}{2}\left(\frac{i_{t}}{k_{t}}-\delta\right)^{2}-i_{t}
$$

\footnotetext{
${ }^{7}$ In addition, the gap between the hiring rate of re-negotiating firms $x_{t}(i)$, and the economy-wide average hiring rate $x_{t}$ generates a spillover effect as well. In particular a loglinear version of the model gives $\left(\hat{x}_{t}^{*}-\hat{x}_{t}\right)=$ $\frac{\lambda \beta w_{s s}}{\kappa x(1-(x+\rho) \lambda \beta)}\left(\hat{w}_{t}-\hat{w}_{t}^{*}\right)$, suggesting that if the contract wage is below the average wage, the hiring rate of that firm will be higher than the average hiring rate.
} 
The aggregate stock of capital evolves as follows:

$$
k_{t+1}=i_{t} \tau_{t}+(1-\delta) k_{t}
$$

The shock $\tau_{t}$ follows the first-order autoregressive process:

$$
\log \tau_{t}=\rho_{x} \log \tau_{t-1}+\epsilon_{t}^{\tau}, \epsilon_{t}^{\tau} \sim i . i . d . N\left(0, \sigma_{\epsilon^{\tau}}^{2}\right)
$$

\subsection{Retailers}

There is a continuum of monopolistically competitive retailers of measure 1 . Retailers buy wholesale goods from entrepreneurs and produce a good of variety $k$. Let $y_{t}(k)$ be the retail good sold by retailer $k$ to households and let $p_{t}(k)$ be its nominal price. The final good, $y_{t}$, is the composite of individual retail goods,

$$
y_{t}=\left[\int_{0}^{1} y_{t}(k)^{\frac{\varepsilon_{t}-1}{\varepsilon_{t}}} d j\right]^{\frac{\varepsilon_{t}}{\varepsilon_{t}-1}},
$$

where $\varepsilon_{t}=\varepsilon \mu_{t} . \mu_{t}$ is a price markup shock, which follows

$$
\log \mu_{t}=\rho_{\mu} \log \mu_{t-1}+\epsilon_{t}^{\mu}, \quad \epsilon_{t}^{\mu} \sim \text { i.i.d. } N\left(0, \sigma_{\epsilon^{\mu}}^{2}\right) .
$$

Following the household's expenditure minimization problem, the corresponding price index, $p_{t}$, is given by

$$
p_{t}=\left[\int_{0}^{1} p_{t}(k)^{1-\varepsilon_{t}} d j\right]^{\frac{1}{1-\varepsilon_{t}}},
$$

and the demand function faced by each retailer is given by

$$
y_{t}(k)=\left(\frac{p_{t}(k)}{p_{t}}\right)^{-\varepsilon_{t}} y_{t} .
$$

Following Calvo (1983), each retailer cannot change prices unless it receives a random signal. The probability of receiving such a signal is $1-\nu$. Thus, in each period, only a fraction of $1-\nu$ of retailers reset their prices, while the remaining retailers keep their prices unchanged. Given the demand function equation (29), the retailer chooses $p_{t}(k)$ to maximize its expected real total profit over the periods during which its prices remain fixed:

$$
E_{t} \sum_{i=0}^{\infty} \nu \Delta_{i, t+i}^{p}\left[\left(\frac{p_{t}(k)}{p_{t+i}}\right) y_{t+i}(j)-m c_{t+i} y_{t+i}(k)\right],
$$

where $\Delta_{t, i}^{p} \equiv \beta^{i} c_{t+i} / c_{t}$ is the stochastic discount factor and the real marginal cost, $m c_{t}$, is the price of wholesale goods relative to the price of final goods $\left(p_{w, t} / p_{t}\right)$. Let $p_{t}^{*}$ be the optimal price chosen 
by all firms adjusting at time $t$. The aggregate price evolves according to:

$$
p_{t}=\left[\nu p_{t-1}^{1-\varepsilon_{t}}+(1-\nu)\left(p_{t}^{*}\right)^{1-\varepsilon_{t}}\right]^{\frac{1}{1-\varepsilon_{t}}} .
$$

\subsection{Government}

I assume that the government spending is $g_{t}$ and it balances its budget,

$$
g_{t}=T_{t}
$$

where $g_{t}$ follows an AR(1) process,

$$
\log g_{t}=\left(1-\rho_{x}\right) \log g_{s s}+\rho_{x} \log g_{t-1}+\epsilon_{t}^{g}, \epsilon_{t}^{g} \sim i . i . d . N\left(0, \sigma_{\epsilon^{g}}^{2}\right) .
$$

\subsection{Monetary Policy Rules}

The central bank is assumed to operate according to the standard Taylor Rule. The central bank adjusts the nominal interest rate, $r_{t}^{n}$, in response to deviations of inflation, $\pi_{t}$, from its steady-state value, $\pi$, and output, $y_{t}$, from its steady-state level, $y$.

$$
\frac{r_{t}^{n}}{r^{n}}=\left(\frac{r_{t-1}^{n}}{r^{n}}\right)^{\rho_{r}}\left(\left(\frac{\pi_{t}}{\pi}\right)^{\rho_{\pi}}\left(\frac{y_{t}}{y}\right)^{\rho_{y}}\right)^{1-\rho_{r}} e^{\epsilon_{t}^{m}},
$$

where $r^{n}, \pi$ and $y$ are the steady-state values of $r_{t}^{n}, \pi_{t}$ and $y_{t}$, and $\epsilon_{t}^{m}$ is a monetary policy shock which follows

$$
\epsilon_{t}^{m} \sim \text { i.i.d. } N\left(0, \sigma_{\epsilon^{m}}\right) .
$$

$\rho_{\pi}, \rho_{y}$ and $\rho_{r}$ are policy coefficients chosen by the central bank.

\subsection{Aggregation and Equilibrium}

The resource constraint for final goods is

$$
z_{t} k_{t}^{\alpha} l_{t}^{1-\alpha}=c_{t}+c_{t}^{e}+i_{t}+g_{t}+\frac{\xi}{2}\left(\frac{i_{t}}{k_{t}}-\delta\right)^{2} k_{t}+\frac{\kappa}{2} x_{t}^{2} n_{t}
$$

Furthermore, for the labor market, we have

$$
l_{t}=n_{t}
$$




\section{Data and Estimation}

\subsection{Data}

I first log-linearize the model around the steady-state. Appendix B and C contain the complete loglinear model, as well as the steady-state conditions. I then adopt a Bayesian approach to estimate the model. I use eight series of quarterly US data: output, consumption, investment, nominal interest rate, inflation, unemployment, real wage and external risk premium. Since the start of the "Great Moderation", the aggregate volatility is significantly different from the earlier periods in the U.S. economy. Thus, in this study I estimate the model using data from 1984Q1 to 2008Q4 to avoid the issue of possible structural breaks associated with the "Great Moderation". Data on output, consumption and investment are expressed in per capita terms using the civilian population aged 15 and up. Output is measured by real GDP. Consumption is measured by real expenditures of non-durable goods and services. Investment is measured by real private investment plus durable consumption goods. The nominal interest rate is measured by Federal Funds rate expressed in quarterly terms. Inflation is the quarter-to-quarter growth rate of the GDP deflator. External finance risk premium is measured as a spread between BAA Corporate Bond yields and Federal Funds rate. The real wage is measured by compensation per hour in the non-farm business sector. Unemployment rate is taken from Bureau of Labour Statistics. The series of output, consumption, investment, unemployment and real wage are logged and detrended using an HP filter with smoothing parameter 1600. The series of nominal interest rate, inflation, and external finance risk premium are demeaned.

Table 1: Calibrated Values

\begin{tabular}{clr}
\hline \hline$\beta$ & discount factor & 0.99 \\
$\sigma$ & inverse of intertemporal substitution of consumption & 1 \\
$\alpha$ & capital share & 0.33 \\
$\delta$ & capital depreciation rate & 0.025 \\
$\epsilon$ & intermediate-good elasticity of substitution & 11 \\
$N / k$ & steady-state ratio of net worth to capital & 0.5 \\
$\eta^{e}$ & survivor rate of entrepreneurs & 0.985 \\
$\rho$ & survival rate of firms & 0.90 \\
$s^{l}$ & steady state job finding rate & 0.95 \\
$q^{l}$ & steady state job filling rate & 0.75 \\
$\sigma_{m}$ & elasticity in matches to unemployment & 0.5 \\
\hline
\end{tabular}

\subsection{Calibrated Values}

As is standard when taking DSGE models to the data, the parameters for which the data used contain only limited information are calibrated to match salient features of the U.S. economy. Table 1 reports the calibrated values. There are 11 parameters. Two of them are for financial market, 
four of them are for labour market, and the rest of the parameters are "conventional" parameters. Financial market parameters include the survival rate of entrepreneurs, $\eta^{e}$, and the steady-state ratio of net worth to capital $N / k$. I set $\eta^{e}=0.985$ so that the steady-state external risk premium matches the sample average spread between the BAA corporate bond yields and Federal Funds rate. I also set $N / k$ to 0.5 , the value that is close to the one used in Christensen and Dib (2008). In calibration, I adopt the following functional form for the external finance premium:

$$
s_{t}=\left(\frac{q_{t} k_{t+1}}{N_{t+1}}\right)^{\chi},
$$

where $\chi$ is the elasticity of external risk premium with respect to leverage and $\chi>0 . \chi$ is a "reduced form" parameter capturing financial market frictions.

For the labor market parameters, I set the elasticity of matches to unemployment, $\sigma_{m}$, to 0.5 , the midpoint of values typically used. The job separation rate, $1-\rho$, is set to be 0.1 , matching the average job duration of two and a half years in the US. The job finding rate $s^{l}$ is set to be 0.95 as in Shimer (2005). The average job filling rate $q^{l}$ is set to 0.75 , which is suggested by den Haan, Ramey and Watson (2000). Following Gertler, Sala and Trigari (2008), I express $\bar{b}$, the steady state flow value of unemployment as

$$
\bar{b}=\tilde{b}\left(p^{l}+\frac{\kappa}{2} x^{2}\right)
$$

where $\tilde{b}$ is the fraction of the contribution of the worker to the job.

I use conventional values for the five "conventional" parameters. The discount factor $\beta$ is set to be 0.99 , which corresponds to an annual real interest rate in the steady-state at four percent. The curvature parameter in the utility function, $\sigma$, is set to 1 . The steady-state depreciation rate, $\delta$, is set to 0.025 , which implies an annual rate of depreciation of ten percent. The parameter of the CobbDouglas function, $\alpha$, is set to be $1 / 3$. The steady-state price mark up $\varepsilon /(\varepsilon-1)$ is 1.1 by setting $\varepsilon=11$.

\begin{tabular}{|c|c|c|c|c|c|c|}
\hline & & \multirow{2}{*}{$\begin{array}{c}\text { Prior } \\
\text { distribution }\end{array}$} & \multicolumn{4}{|c|}{ Posterior distribution } \\
\hline & & & Mode & Mean & $5 \%$ & $95 \%$ \\
\hline Risk premium elasticity & $\chi$ & gamma $(0.05,0.04)$ & 0.1367 & 0.1394 & 0.1081 & 0.1705 \\
\hline Bargaining power parameter & $\eta$ & beta $(0.50,0.10)$ & 0.7479 & 0.7430 & 0.6573 & 0.8338 \\
\hline Relative flow value of unemployment & $\tilde{b}$ & beta $(0.50,0.10)$ & 0.6611 & 0.6446 & 0.5051 & 0.7895 \\
\hline Calvo wage parameter & $\lambda$ & beta $(0.75,0.05)$ & 0.5795 & 0.5786 & 0.5421 & 0.6137 \\
\hline Calvo price parameter & $\nu$ & beta $(0.66,0.05)$ & 0.6642 & 0.6586 & 0.6257 & 0.6944 \\
\hline Capital adj. cost parameter & $\xi$ & norm $(0.25,0.05)$ & 0.2111 & 0.2102 & 0.1321 & 0.2956 \\
\hline Habit parameter & $h$ & beta $(0.65,0.1)$ & 0.9143 & 0.9104 & 0.8673 & 0.9543 \\
\hline Taylor rule inertia & $\rho_{r}$ & beta $(0.75,0.1)$ & 0.4619 & 0.4532 & 0.3497 & 0.5533 \\
\hline Taylor rule inflation & $\rho_{\pi}$ & $\operatorname{gamma}(1.5,0.1)$ & 1.9632 & 1.9754 & 1.8335 & 2.1131 \\
\hline Taylor rule output gap & $\rho_{y}$ & norm $(0.125,0.15)$ & 0.1767 & 0.1816 & 0.1272 & 0.2375 \\
\hline
\end{tabular}

Table 2: Prior and Posterior Distribution of Structural Parameters: Baseline 
Table 3: Prior and Posterior Distribution of Shock Parameters: Baseline

\begin{tabular}{lcccccc}
\hline \hline & & Prior & \multicolumn{4}{c}{ Posterior distribution } \\
\cline { 3 - 7 } & & distribution & Mode & Mean & $5 \%$ & $95 \%$ \\
\hline \multicolumn{2}{c}{ Panel A: Autoregressive parameters } & & & & \\
Technology & $\rho_{z}$ & beta $(0.6,0.2)$ & 0.4375 & 0.4340 & 0.3335 & 0.5350 \\
Preference & $\rho_{e}$ & beta $(0.6,0.2)$ & 0.4193 & 0.4288 & 0.2051 & 0.6481 \\
Investment & $\rho_{\tau}$ & beta $(0.6,0.2)$ & 0.9403 & 0.9380 & 0.9149 & 0.9631 \\
Government & $\rho_{g}$ & beta $(0.6,0.2)$ & 0.8653 & 0.8554 & 0.7663 & 0.9545 \\
Financial & $\rho_{\gamma}$ & beta $(0.6,0.2)$ & 0.6763 & 0.6541 & 0.5310 & 0.7801 \\
Bargaining power & $\rho_{\varepsilon}$ & beta $(0.6,0.2)$ & 0.8452 & 0.8399 & 0.7476 & 0.9313 \\
Markup & $\rho_{\mu}$ & beta $(0.6,0.2)$ & 0.6976 & 0.6920 & 0.5964 & 0.7893 \\
Panel B: Standard deviations & & & & \\
Technology & $\sigma_{\epsilon^{z}}$ & invg $(0.005,2)$ & 0.47 & 0.48 & 0.42 & 0.54 \\
Monetary & $\sigma_{\epsilon^{m}}$ & invg $(0.005,2)$ & 0.33 & 0.34 & 0.27 & 0.41 \\
Investment & $\sigma_{\epsilon^{\tau}}$ & invg $(0.005,2)$ & 1.03 & 1.04 & 0.78 & 1.29 \\
Preference & $\sigma_{\epsilon^{e}}$ & invg $(0.005,2)$ & 6.40 & 6.81 & 4.05 & 9.54 \\
Government & $\sigma_{\epsilon^{g}}$ & invg $(0.005,2)$ & 0.99 & 1.00 & 0.89 & 1.12 \\
Financial & $\sigma_{\epsilon^{\gamma}}$ & invg $(0.005,2)$ & 0.36 & 0.38 & 0.28 & 0.48 \\
Bargaining power & $\sigma_{\epsilon^{\varepsilon}}$ & invg $(0.005,2)$ & 1.56 & 1.64 & 1.23 & 2.04 \\
Markup & $\sigma_{\epsilon^{\mu}}$ & $\operatorname{invg}(0.005,2)$ & 0.10 & 0.11 & 0.08 & 0.14 \\
\hline \multicolumn{5}{c}{ Log data density } & \multicolumn{5}{c}{3205.53} \\
\hline
\end{tabular}

\subsection{Priors}

I estimate the remaining parameters: the elasticity of external risk premium, $\chi$; the habit persistence parameter $h$, the capital adjustment cost parameter $\xi$; the Calvo price and wage parameter $\nu$ and $\lambda$; and the Taylor rule parameters, $\rho_{\pi}, \rho_{y}$, and $\rho_{r}$. Following Gertler, Sala and Trigari (2008), I also estimate two labour market parameters, the bargaining power parameter $\eta$ and the relative flow value of unemployment $\tilde{b}$. The first-order autocorrelations of all the exogenous shocks and their respective standard deviations are estimated as well. Tables 2 and 3 report the prior and the posterior distributions for each of them. Among the behavioral parameters listed in Table 2, the Taylor rule parameters, the Calvo price, habit persistence parameter and capital adjustment cost parameters are rather conventional. For the priors of these parameters, I closely follow the existing literature. The rest of the parameters are less conventional. In the literature, $\chi$ is typically calibrated at 0.05 as in BGG, although some other studies suggest that it can be much higher. ${ }^{8}$ I assume that $\chi$ follows a gamma distribution with mean 0.05 but with a relatively large standard deviation of 0.04 so as not to exclude values well above 0.05 . For the priors for $\lambda, \eta$ and $\tilde{b}$, I closely follow Gertler, Sala and Trigari (2008). I assume that $\lambda$ follows a Beta distribution with mean 0.75 and a standard

\footnotetext{
${ }^{8}$ De Graeve (2008) estimates $\chi$ to be at 0.1 .
} 
deviation of 0.05 , suggesting that firms negotiate wage contract with workers every 4 quarters on average. For $\eta$, I use a Beta distribution with mean 0.5 and a standard deviation of 0.1 , implying that workers and firms have equal bargaining power. For $\tilde{b}$, the flow value of being unemployed, I use a Beta distribution with mean 0.5 and a standard deviation of 0.1 suggesting that the worker's contribution to the firm is 50 per cent.

The priors of the shock processes are presented in Table 3. I follow Smets and Wouters (2007), the priors on the shock processes are harmonized as much as possible. The standard deviation of the shocks are assumed to follow an Inverted Gamma distribution with a mean of 0.5 percent and two degrees of freedom. The persistence of the shock processes is Beta distributed with mean 0.6 and standard deviation 0.2 .

I use Dynare 4.3 to estimate the model and use Metropolis-Hastings algorithm to perform simulations. The total number of draws is 100,000 and the first 20 percent draws are neglected. A step size of 0.4 results in a acceptance rate of 0.26 .

\section{Estimation Results}

\subsection{Posterior Estimates of the Parameters}

Table 2 gives the mode, the mean and the 5 and 95 percentiles of the posterior distribution of the behavioral parameters. In what follows, I focus on the estimates of the "less conventional" parameters: $\chi, \lambda, \eta$ and $\tilde{b}$. The mean of estimate of the risk premium elasticity parameter $\chi$ is 0.137 . Christensen and Dib (2008) use maximum likelihood procedure to estimate a sticky-price model with a financial accelerator on the U.S. data and suggest that $\chi$ is around 0.042. Compared to their value, $\chi=0.137$ is much larger. Since Christensen and Dib (2008) do not use any financial data in their estimation, this much larger elasticity might have resulted from the information contained in the financial data I used in the estimation. Calvo wage contract parameter, $\lambda$, is estimated to be 0.58 , suggesting a mean of about two and a half quarters between wage contracting periods, or the probability of nominal wage contract adjustment is 42 per cent in each quarter. ${ }^{9}$ The relative flow value of unemployment $\tilde{b}$ is estimated to be 0.66 , suggesting that the flow value of unemployment is 66 per cent of the worker's marginal flow value to the firm. This value is close to 0.7 , the value proposed by Hall (2008). ${ }^{10}$ The bargaining power parameter $\eta$ is estimated at 0.75 , not far from the range considered in the literature, 0.5-0.7. Since the labour market specification in the model is similar to Gertler, Sala and Trigari (2008), I also compare the estimated values of $\lambda, \eta$, and $\tilde{b}$ with their estimates. In their paper, $\lambda=0.72, \eta=0.9$, and $\tilde{b}=0.73$. Note that the bargaining power estimate $\eta$ is well above the normal range considered in the literature. The larger is $\eta$, the

\footnotetext{
${ }^{9}$ Although the micro evidence in Barattieri et al (2010) suggest that the probability of wage adjustment is about 18 per cent per quarter, studies based aggregate data suggest that wage adjust more frequently. For example, Christiano et al (2005) suggest that the probability of wage adjustment is 36 per cent and Smets and Wouters (2007) suggest that it is 26 per cent.

${ }^{10} \tilde{b}$ in Hall (2008) includes utility from leisure, thus it is larger than the value (0.4) argued by Shimer, which interprets $\tilde{b}$ as unemployment benefit.
} 
more sensitive are wages to movements of the shadow value of labour, and thus less sensitive is employment. This might result in a larger estimate of $\lambda$ in their results, given that a larger $\lambda$ reduces the sensitivity of wages.

The estimates of the "conventional" parameters are consistent with other studies. The degree of price stickiness, $\nu$, is estimated to be 0.66 , implying an average price adjustment duration of every three quarters. The capital adjustment cost parameter, $\xi$, is estimated to be around 0.21 . For the monetary policy reaction function parameters, $\rho_{\pi}$, the Taylor rule inflation parameter, is estimated to be 1.96 , and the reaction coefficient to output gap, $\rho_{y}$, is estimated to be 0.18 , suggesting that the policy rate responds very little to output gap. There is a relatively low degree of interest rate smoothing, as the coefficient on the lagged interest rate is estimated to be 0.46 .

Table 3 presents the estimates of the shock processes. The most persistent shock is the investment specific shocks, with an AR(1) coefficient of 0.94. The financial wealth shock has a persistence of 0.68 and standard deviation of 0.0036 . In contrast, the new labour market shocks, the bargaining power shock is more persistent and volatile, with an $\mathrm{AR}(1)$ coefficient of 0.85 , and a standard deviation of 0.016 .

\subsection{Empirical Fit}

One way to assess how the model captures the data is to compare the volatilities of the model against the data. Table 4 reports this information. Overall the model does a decent job in matching the data. In particular, for the key labour market variables, the model captures the fact that both unemployment and vacancies are highly volatile and real wage are relatively rigid. The model slightly underestimate the relative volatilities of unemployment and vacancy ( 7.35 in the model versus 10.31 in the data for unemployment, and 9.29 in the model versus 12.52 in the data for vacancies). This might be due to the fact that the model overestimates the volatility of the real wage ( 0.92 in the model versus 0.57 in the data). For the key financial market variables, the model generated risk premium is reasonably close to the one in the data ( 0.36 versus 0.45 in the data).

Table 4: Relative Standard Deviations: Model vs Data

\begin{tabular}{lcccrrccc}
\hline \hline & $y$ & $i$ & $w$ & \multicolumn{1}{c}{$v$} & \multicolumn{1}{c}{$u$} & $r_{n}$ & $\pi$ & $s$ \\
\hline Data & 1 & 4.41 & 0.57 & 12.52 & 10.31 & 0.70 & 0.30 & 0.45 \\
Baseline & 1 & 5.57 & 0.92 & 9.29 & 7.35 & 0.43 & 0.29 & 0.36 \\
\hline
\end{tabular}

I then explore the contemporaneous correlation of the key labour and financial market variables with output and report in Table 5. The model matches well the contemporaneous correlation of unemployment and vacancies (-0.92 in the model versus -0.88 in the data). The model also matches the fact that unemployment is countercyclical and vacancy is procyclical. The model seems to have difficulties in capturing the fact that real wage and output has a negative correlation (-0.22). Instead, the model generates a very strong positive correlation between real wage and output $(0.62)$. The 
Table 5: Correlation Coefficients: Model vs Data

\begin{tabular}{llllll}
\hline \hline Data/Model & $y$ & $u$ & $v$ & $w$ & $s$ \\
\hline$y$ & 1 & -0.79 & 0.79 & -0.22 & -0.60 \\
& - & $(-0.53)$ & $(0.44)$ & $(0.62)$ & $(-0.56)$ \\
$u$ & - & 1 & -0.88 & 0.13 & 0.85 \\
& - & - & $(-0.92)$ & $(0.27)$ & $(0.55)$ \\
$v$ & - & - & 1 & -0.45 & -0.76 \\
& - & - & - & $(-0.32)$ & $(-0.54)$ \\
$w$ & - & - & - & 1 & 0.18 \\
& - & - & - & - & $(-0.17)$ \\
$s$ & - & - & - & - & 1 \\
\hline
\end{tabular}

model does capture the positive correlation between real wage and unemployment and the negative correlation between real wage and vacancy.

The last column of Table 5 presents the correlations of the risk premium with output, unemployment, vacancy and real wage. The model appears to capture well the fact that risk premium is countercyclical. It also captures the positive correlation between unemployment and risk premium, and the negative correlation between vacancy and risk premium.

\subsection{Sources of Labour Market Fluctuations}

\subsubsection{Forecasting error variance decomposition}

Table 6 presents the results for the forecast error variance decomposition for the infinite horizon based on the mode of the model's posterior distribution. For the key labour market variables: unemployment and vacancies, the bargaining power and financial wealth shocks are the two dominating shocks. The bargaining power shock explains more than 40 per cent of the variability in both unemployment and vacancies. The financial shock is next in importance. It explains 33 per cent of the variations in unemployment, and 31 per cent of the variations in vacancies. The financial shock is also the most important shock in explaining the fluctuations in real wage, accounting for almost 70 per cent of the variations in real wage.

Table 6 also displays the results for the other key macro economy variables. Again, the financial shocks appears to be the most important shock explaining the variations in those macro variables as well. It accounts for about 63 per cent of the variation in output, 38 per cent in consumption and 50 per cent in investment. ${ }^{11}$

Table 7 reports the forecast error variance decomposition for unemployment at different fixed horizons. I consider three horizons: 4 quarters, which represents the short-run (within a year) impact of the shocks; 8 quarters, which represents the business cycle frequency; and 5 years, which

\footnotetext{
${ }^{11}$ This result is consistent with Jermann and Quadrini (2012), which find that the financial shock explains 46.4 per cent of the variation in GDP in the U.S.
} 
Table 6: Variance Decomposition of the Key Labour Market Variables

\begin{tabular}{lrrrrrrrr}
\hline \hline & Tech. & Mon. & Fin. & Inv. & Pref. & Gov. & Bar. & Mar. \\
\hline$y$ & 7.24 & 1.33 & 63.4 & 7.27 & 1.86 & 0.23 & 17.23 & 1.42 \\
$c$ & 0.37 & 0.71 & 37.8 & 19.2 & 31.8 & 3.75 & 6.06 & 0.30 \\
$i$ & 3.98 & 1.02 & 50.2 & 18.7 & 17.2 & 3.26 & 4.77 & 0.91 \\
$\pi$ & 2.31 & 36.09 & 29.8 & 7.67 & 12.49 & 1.72 & 9.47 & 0.43 \\
$r^{n}$ & 0.76 & 1.44 & 51.1 & 14.19 & 22.78 & 3.02 & 6.15 & 0.61 \\
$u$ & 0.71 & 0.83 & 32.8 & 7.02 & 10.93 & 1.40 & 43.43 & 2.91 \\
$v$ & 0.75 & 0.82 & 31.4 & 6.67 & 10.29 & 1.32 & 44.43 & 4.29 \\
$w$ & 1.43 & 1.41 & 69.8 & 7.48 & 7.56 & 0,98 & 5.35 & 5.98 \\
\hline
\end{tabular}

represents the long-run effects. One interesting finding is that in the short run, the financial wealth shock explains only a small fraction of the fluctuations in unemployment. Unemployment is mainly explained by the bargaining power shock. However, over time, more variability is accounted for by the financial shock: it accounts for about 23 per cent of the variations in unemployment at 8 quarters forecast horizon, and 31 per cent at horizon of 5 years. In contrast, the bargaining power power shock explains less variability in unemployment over time. Table 8 shows that the same is true for vacancies.

Table 7: Variance Decomposition for Unemployment at Different Horizons

\begin{tabular}{lrrr}
\hline \hline & \multicolumn{3}{c}{ Horizons } \\
\hline & 4 quarters & 8 quarters & 5 years \\
\hline Technology & 0.37 & 0.79 & 0.76 \\
Monetary & 0.80 & 0.82 & 0.82 \\
Financial & 13.24 & 22.88 & 31.09 \\
Investment & 2.07 & 3.56 & 6.75 \\
Preferences & 0.45 & 2.00 & 8.68 \\
Government & 0.12 & 0.40 & 1.25 \\
Bargaining & 69.5 & 64.26 & 47.68 \\
Markup & 13.45 & 5.31 & 3.16 \\
\hline
\end{tabular}

\subsubsection{Historical Decomposition}

To further understand the role of the financial wealth shock in explaining unemployment fluctuations, I conduct the historical decomposition for unemployment in the period 1984Q1 to 2008Q4 (Figure 1). I categorize the investment-specific, preference, and government spending shocks as "demand" shock because they have a positive effects on both output and inflation. The three recessions during the sample period are displayed in shaded area in Figure 1. The financial shock 
Table 8: Variance Decomposition for Vacancies at Different Horizons

\begin{tabular}{lrrr}
\hline \hline & \multicolumn{3}{c}{ Horizons } \\
\hline & 4 quarters & 8 quarters & 5 years \\
\hline Technology & 0.76 & 0.86 & 0.79 \\
Monetary & 0.79 & 0.81 & 0.80 \\
Financial & 16.30 & 24.36 & 29.65 \\
Investment & 2.47 & 3.92 & 6.38 \\
Preferences & 0.83 & 2.69 & 8.76 \\
Government & 0.19 & 0.50 & 1.24 \\
Bargaining & 67.87 & 60.55 & 47.79 \\
Markup & 10.8 & 6.36 & 4.59 \\
\hline
\end{tabular}

contributes significantly to the rise in unemployment rate in every economic downturn in the sample period. In particular, it turns out to be the main driving force for the rise in the unemployment rate in the past two recent recessions.

\subsection{Amplification Effect of the Financial Accelerator}

I examine this issue by simulating the response of several key variables after the financial shock. I analyze the role of financial frictions by examining both the baseline model and the same model with $\chi$ reduced to 0.05 , the value usually suggested by the literature ${ }^{12}$. Figure 2 illustrates the response of the model economy to an negative financial shock. The solid line is the baseline model. The dotted line is the model with $\chi=0.05$. In both cases, following a negative financial wealth shock, the survivor rate of the entrepreneurs decreases, causing the aggregate net worth to fall. This drives up the external finance premium, forcing entrepreneurs to reduce their demand for capital by reducing investment. The fall in demand for capital is accompanied by the fall in demand for labor. Asset price falls with the the reduced demand for capital, and this further decreases entrepreneurs' net worth (Financial accelerator effect). Due to the fall in the aggregate demand for labor, employment agencies post fewer vacancies. This reduces the probability for a worker to find a job, leading the unemployment rate to rise. Notice that after the shock, the initial responses of net worth and leverage ratio are similar for both cases; however, the response of risk premium is significantly greater in the baseline than in the alternative model due to the higher value of $\chi$. The stronger rise in the risk premium leads to a stronger response in demand for capital. Asset price declines further, driving net worth further down. The amplification effect of the financial accelerator is more significant in the baseline model and this leads to stronger responses of the other variables to the financial shock.

\footnotetext{
${ }^{12}$ The rest of the parameters are the same for both models.
} 


\subsection{Staggered Wage Contracting}

In this section I examine the role of staggered wage contracting by comparing the baseline model and the model with the Calvo wage parameter $\lambda$ is set to 0 (wage is flexible). Figure 3 plots the impulse responses of the key variables to a financial shock. Compared to the baseline case, the responses in unemployment and vacancies are significantly dampened in the model without wage rigidity. This suggests that the staggered wage contracting play a similar role as the financial accelerator in amplifying the impact of a financial shock on unemployment.

However, the above comparison is based on the baseline model estimates, i.e. the bargaining power parameter $\eta$, and the flow value of unemployment $\tilde{b}$ are fixed. As suggested in Hagedorn and Manovskii (2008), when $\tilde{b}$ is close to unity, the value of unemployment is very close to that of employment to the worker. Thus, in this case labour supply is very elastic. The smaller is $\eta$, the less responsive are wages to shocks, and thus the more sensitive is employment. I next estimate the model with flexible wages $(\lambda=0)$. Table 9 presents the results. Compared to the baseline case, the estimates of the most parameters do not change much. However, the worker's bargaining power parameter $\eta$ falls from 0.75 to 0.13 , and the flow value of unemployment $\tilde{b}$ increases from 0.66 to 0.95. These results are consistent with the findings in Gertler, Sala and Trigari (2008), i.e. when the wage rigidity is absent, $\tilde{b}$ increases and $\eta$ decreases.

Table 9: Comparison: Flexible Wages vs Baseline

\begin{tabular}{|c|c|c|c|c|c|}
\hline & \multicolumn{2}{|c|}{ Structural parameters } & & \multicolumn{2}{|c|}{ Shock process } \\
\hline & Flexible Wage & Baseline & & Flexible Wage & Baseline \\
\hline & Mode & Mode & & Mode & Mode \\
\hline$\chi$ & 0.1500 & 0.1367 & $\rho_{z}$ & 0.4566 & 0.4375 \\
\hline$\lambda$ & - & 0.5795 & $\rho_{e}$ & 0.6361 & 0.4193 \\
\hline$\eta$ & 0.1246 & 0.7479 & $\rho_{\tau}$ & 0.9330 & 0.9403 \\
\hline$\dot{\tilde{b}}$ & 0.9529 & 0.6611 & $\rho_{g}$ & 0.8339 & 0.8653 \\
\hline$\rho_{r}$ & 0.3864 & 0.4619 & $\rho_{\gamma}$ & 0.7024 & 0.6763 \\
\hline$\rho_{\pi}$ & 2.0752 & 1.9632 & $\rho_{\omega}$ & 0.9518 & 0.8452 \\
\hline$\rho_{y}$ & 0.1352 & 0.1767 & $\rho_{\mu}$ & 0.8751 & 0.6976 \\
\hline$h$ & 0.8486 & 0.9143 & $\sigma_{\epsilon^{z}}$ & 0.48 & 0.47 \\
\hline$\nu$ & 0.5204 & 0.6642 & $\sigma_{\epsilon^{m}}$ & 0.40 & 0.33 \\
\hline$\xi$ & 0.2426 & 0.2111 & $\sigma_{\epsilon^{\tau}}$ & 1.00 & 1.03 \\
\hline & & & $\sigma_{\epsilon^{e}}$ & 8.63 & 6.40 \\
\hline & & & $\sigma_{\epsilon^{g}}$ & 1.06 & 0.99 \\
\hline & & & $\sigma_{\epsilon^{\gamma}}$ & 0.31 & 0.36 \\
\hline & & & $\sigma_{\epsilon^{\omega}}$ & 3.13 & 1.56 \\
\hline & & & $\sigma_{\epsilon^{\mu}}$ & 0.18 & 0.10 \\
\hline & & & nsity & 3153.35 & 3205.59 \\
\hline
\end{tabular}




\section{Issues}

In this section I address several issues involving the robustness of the results.

\subsection{Elasticity of External Risk Premium}

The elasticity of the external risk premium $\chi$ is the key parameter of the financial accelerator mechanism. In BGG, $\chi$ is a "reduced form" parameter that captures financial frictions. It is determined by the "deep" parameters in the original BGG model: the variance of idiosyncratic shocks to the return on capital, the bankruptcy costs, and entrepreneurs' survival rate. In the literature, it is typically calibrated at $0.05 .^{13}$ The examples of estimated models based on BGG for US data are Christensen and Dib (2008), De Graeve (2008) and Queijo (2009). None of these paper use financial data. Christensen and Dib (2008) and Queijo (2009) estimate $\chi$ to be around 0.04. ${ }^{14}$ De Graeve (2008) estimates $\chi$ to be at 0.1 . Compared to these values, the estimate of $\chi=0.137$ in the baseline model is substantially higher. One potential explanation for the high value of $\chi$ might be the inclusion of the financial data. In other words, the non financial variables used in the estimation in the abovementioned studies contain very limited information on financial frictions, thus $\chi$ is underestimated.

In order to explore this idea, I re-estimate the model but taking out the financial wealth shock. I compare the results from the alternative model (NoFS model) with the baseline model in Table 10. The most noticeable change is that the estimate of the elasticity of external financing $\chi$ falls to 0.052 from 0.137 , suggesting that it is important to include financial time series to identify financial frictions.

Of course it could be other reasons leading to the large value of $\chi$. For example, it could be due to the particular financial data series used in the estimation, or the fact the prior used is not appropriate or simply the way that the data is detrended. Thus, to further get a sense of how robust the estimated $\chi$ is, I conduct the following three exercises. In the first exercise, instead of using the corporate bond yields, I use the difference between US business prime lending rate and the federal funds rate to proxy the external finance premium. The estimated $\chi$ is 0.094 and reported in Table 11. It is smaller than that in the baseline case but still much larger than the conventional value 0.05. It is also interesting to note that in the data the volatility of the risk premium based on the prime lending rate is smaller than that based on the BAA corporate bond yields, 0.0015 versus 0.0039 . This could be the reason why the estimated $\chi$ is smaller when using the prime lending rate. The smaller $\chi$ is, the less responsive the external risk premium is to firms' balance-sheet positions, and this leads to a lower volatility in risk premium.

In the second exercise, I test how sensitive the result is to the priors. Keeping the priors of the rest of the parameters fixed at the baseline values, I loose the prior for $\chi$ to a gamma distribution with mean 0.05 and a standard deviation of 0.1 . I estimate the model again and report the estimated

\footnotetext{
${ }^{13}$ See for examples, Bernanke, Gertler and Gilchrist (1999) and Bernanke and Gertler (2000).

${ }^{14}$ Queijo (2009) does not estimate $\chi$ directly; instead she estimates parameters for bankruptcy costs and survival rate of entrepreneurs. The estimates of these parameters imply that $\chi$ is 0.04 .
} 
Table 10: Comparison: NoFS Vs Baseline

\begin{tabular}{ccccccc}
\hline \hline \multicolumn{3}{c}{ Structural parameters } & & \multicolumn{2}{c}{ Shock process } \\
\cline { 1 - 3 } \cline { 5 - 6 } & NoFS & Baseline & & NoFS & Baseline \\
\cline { 2 - 3 } \cline { 5 - 6 } & Mode & Mode & & Mode & Mode \\
\hline$\chi$ & 0.052 & 0.1367 & & $\rho_{z}$ & 0.5942 & 0.4375 \\
$\tilde{b}$ & 0.703 & 0.7479 & & $\rho_{e}$ & 0.946 & 0.4193 \\
$\lambda$ & 0.659 & 0.6611 & & $\rho_{\tau}$ & 0.884 & 0.9403 \\
$\lambda$ & 0.633 & 0.5795 & & $\rho_{g}$ & 0.881 & 0.8653 \\
$\nu$ & 0.716 & 0.6642 & & $\rho_{\gamma}$ & - & 0.6763 \\
$\xi$ & 0.220 & 0.2111 & $\rho_{\omega}$ & 0.816 & 0.8452 \\
$h$ & 0.430 & 0.9143 & $\rho_{\mu}$ & 0.519 & 0.9676 \\
$\rho_{r}$ & 0.490 & 0.4619 & $\sigma_{\epsilon^{z}}$ & 0.46 & 0.47 \\
$\rho_{\pi}$ & 1.967 & 1.9632 & $\sigma_{\epsilon^{m}}$ & 0.32 & 0.33 \\
$\rho_{y}$ & 0.088 & 0.1767 & $\sigma_{\epsilon^{\tau}}$ & 0.98 & 1.03 \\
& & $\sigma_{\epsilon^{e}}$ & 2.02 & 6.40 \\
& & $\sigma_{\epsilon^{g}}$ & 1.00 & 0.99 \\
& & $\sigma_{\epsilon^{\gamma}}$ & - & 0.36 \\
& & $\sigma_{\epsilon^{\omega}}$ & 2.00 & 1.56 \\
& & $\sigma_{\epsilon^{\mu}}$ & 0.11 & 0.10 \\
\hline
\end{tabular}

Table 11: BAA versus Prime Lending Rate

\begin{tabular}{lll}
\hline \hline & Prime lending rate & BAA (baseline) \\
\hline Standard deviation in data & 0.0015 & 0.0039 \\
Estimated mode & 0.094 & 0.137 \\
\hline
\end{tabular}


mode and the standard deviation for $\chi$ in Table $12 .{ }^{15}$ With the loose prior, the estimated $\chi$ is 0.144 , close to the value in the baseline case.

Table 12: Robustness of Priors

\begin{tabular}{lll}
\hline \hline & Baselin Prior & Loose Prior \\
\cline { 2 - 3 } Prior & $(0.05,0.04)$ & $(0.05,0.10)$ \\
\hline Mode & 0.137 & 0.144 \\
Sd & $(0.019)$ & $(0.021)$ \\
\hline
\end{tabular}

Third, instead of using HP filter to detrend the data, I follow Smets and Wouters (2007) by measuring output, consumption, investment, unemployment, and real wage in first difference and keeping nominal interest rate, inflation and external risk premium in levels. I re-estimate the model and report the results in Table 13. Compared to the baseline case, the results for behavior parameters and shock process are more or less the same. The estimated $\chi$ is 0.096 , slightly lower than 0.137 in the baseline case; however, the financial shock still explains about 20 per cent of the fluctuations in unemployment and vacancies.

Table 13: Comparison: First Difference vs Baseline

\begin{tabular}{|c|c|c|c|c|c|}
\hline & \multicolumn{2}{|c|}{ Structural parameters } & & \multicolumn{2}{|c|}{ Shock process } \\
\hline & First Difference & Baseline & & First Difference & Baseline \\
\hline & Mode & Mode & & Mode & Mode \\
\hline$\chi$ & 0.0962 & 0.1367 & $\rho_{z}$ & 0.9599 & 0.4375 \\
\hline$\eta$ & 0.7241 & 0.7479 & $\rho_{e}$ & 0.8596 & 0.4193 \\
\hline$\tilde{b}$ & 0.6098 & 0.6611 & $\rho_{\tau}$ & 0.9769 & 0.9403 \\
\hline$\lambda$ & 0.5903 & 0.5795 & $\rho_{g}$ & 0.9751 & 0.8653 \\
\hline$\nu$ & 0.6636 & 0.6642 & $\rho_{\gamma}$ & 0.8413 & 0.6763 \\
\hline$\xi$ & 0.2036 & 0.2111 & $\rho_{\omega}$ & 0.9149 & 0.8452 \\
\hline$h$ & 0.8078 & 0.9143 & $\rho_{\mu}$ & 0.8817 & 0.9676 \\
\hline$\rho_{r}$ & 0.5793 & 0.4619 & $\sigma_{\epsilon^{z}}$ & 0.51 & 0.47 \\
\hline$\rho_{\pi}$ & 1.9670 & 1.9632 & $\sigma_{\epsilon^{m}}$ & 0.28 & 0.33 \\
\hline \multirow[t]{7}{*}{$\rho_{y}$} & 0.0237 & 0.1767 & $\sigma_{\epsilon^{\tau}}$ & 1.68 & 1.03 \\
\hline & & & $\sigma_{\epsilon^{e}}$ & 4.26 & 6.40 \\
\hline & & & $\sigma_{\epsilon^{g}}$ & 1.11 & 0.99 \\
\hline & & & $\sigma_{\epsilon^{\gamma}}$ & 0.32 & 0.36 \\
\hline & & & $\sigma_{\epsilon^{\omega}}$ & 1.85 & 1.56 \\
\hline & & & $\sigma_{\epsilon^{\mu}}$ & 0.12 & 0.10 \\
\hline & & & data density & 3080.79 & 3205.59 \\
\hline
\end{tabular}

\footnotetext{
${ }^{15}$ I have also conducted the same exercise for the NoFS model. The estimated mode for $\chi$ is 0.0524 under the looser prior, quite close to the value of 0.0521 under the baseline prior.
} 


\subsection{Estimations of an Alternative Sample}

Given that $\chi$ can be sensitive to the sample period, in this section I estimate the model over the period of 1966Q2 to 1979Q2. This is the so-called "Great Inflation" period (Smets and Wouters 2007). Table 14 presents the comparison of the standard deviations of the key variables between the baseline sample and the alternative sample. It shows that output and inflation volatility fall considerably in our baseline sample. The volatilities of the unemployment and vacancies fall as well, although the volatility in real wage appears to stay the same across the two samples. Table 15

Table 14: Standard Deviations of Subsamples

\begin{tabular}{lrr}
\hline \hline & $66: 1-79: 2$ & $84: 1-08: 3$ \\
\hline Output & 0.016 & 0.0087 \\
Consumption & 0.0075 & 0.0061 \\
Investment & 0.060 & 0.0384 \\
Real wage & 0.005 & 0.005 \\
Vacancy & 0.138 & 0.109 \\
Unemployment & 0.132 & 0.0897 \\
Nom. Interest rate & 0.005 & 0.0061 \\
Inflation & 0.006 & 0.0026 \\
Risk premium & 0.0053 & 0.0039 \\
\hline
\end{tabular}

compares the modes of the posterior distribution of the model parameters over these two samples. Similar to Smets and Wouters (2007), the most significant differences between the two samples are in the variances of the shock processes. The standard deviations of the most of the shocks considered in the model fall in the second period. However, the standard deviation of the financial shock rises by from 0.24 to 0.36 . The persistence of the financial shock slightly increases as well, from 0.64 to 0.68 . For the estimated behavioral parameters, the noticeable changes are that $\chi$, the elasticity of external risk premium, rises from 0.097 in the "Great Inflation" period to 0.137 in the "Great Moderation" period, and $\rho_{\pi}$, the Taylor rule inflation coefficient, rises from 1.61 to 1.96, suggesting a more aggressive response to inflation during the "Great Moderation" period.

A more volatile and persistent financial wealth shock, together with a more elastic external risk premium, results in that a much larger fraction of the labour market fluctuations is explained by the financial shock in the "Great Moderation" period (Table 16 ).

\section{Concluding Remarks}

In this paper, I find that shocks on the net worth of the firms can explain a significant portion of the labour market fluctuations in the US. The financial accelerator mechanism amplifies the financial shock and generates large fluctuations in the labour market. The key parameter related to the financial accelerator mechanism in the model is the elasticity of the external financing, $\chi$. The larger the $\chi$ is, the more elastic is the risk premium with respect to leverage, and the more powerful 
Table 15: Subsample Estimates

\begin{tabular}{|c|c|c|c|c|c|}
\hline & \multicolumn{2}{|c|}{ Structural parameters } & & \multicolumn{2}{|c|}{ Shock process } \\
\hline & 1966:1-1979:2 & 1984:1-2008:4 & & 1966:1-1979:2 & 1984:1-2008:4 \\
\hline & Mode & Mode & & Mode & Mode \\
\hline$\chi$ & 0.0973 & 0.1367 & $\rho_{z}$ & 0.4218 & 0.4375 \\
\hline$\lambda$ & 0.5127 & 0.5795 & $\rho_{e}$ & 0.2593 & 0.4193 \\
\hline$\nu$ & 0.6892 & 0.6642 & $\rho_{\tau}$ & 0.9868 & 0.9403 \\
\hline$\xi$ & 0.2299 & 0.2111 & $\rho_{g}$ & 0.8035 & 0.8653 \\
\hline$\rho_{r}$ & 0.4068 & 0.4619 & $\rho_{\gamma}$ & 0.6352 & 0.6763 \\
\hline$\rho_{\pi}$ & 1.6136 & 1.9632 & $\rho_{\omega}$ & 0.8935 & 0.8452 \\
\hline$\rho_{y}$ & 0.1082 & 0.1767 & $\rho_{\mu}$ & 0.3585 & 0.6976 \\
\hline$h$ & 0.8486 & 0.9143 & $\sigma_{\epsilon^{z}}$ & 0.80 & 0.47 \\
\hline$\eta$ & 0.7442 & 0.7479 & $\sigma_{\epsilon^{m}}$ & 0.39 & 0.33 \\
\hline$\tilde{b}$ & 0.6020 & 0.6611 & $\sigma_{\epsilon^{\tau}}$ & 2.68 & 1.03 \\
\hline & & & $\sigma_{\epsilon^{e}}$ & 3.88 & 6.40 \\
\hline & & & $\sigma_{\epsilon^{g}}$ & 1.33 & 0.99 \\
\hline & & & $\sigma_{\epsilon \gamma}$ & 0.24 & 0.36 \\
\hline & & & $\sigma_{\epsilon^{\omega}}$ & 2.55 & 1.56 \\
\hline & & & $\sigma_{\epsilon^{\mu}}$ & 0.19 & 0.10 \\
\hline
\end{tabular}

Table 16: Variance Decomposition: Subsamples

\begin{tabular}{lrrrccc}
\hline \hline & \multicolumn{3}{c}{$1966: 1-1979: 2$} & \multicolumn{3}{c}{$1984: 1-2008: 4$} \\
\cline { 2 - 7 } & Unemployment & Vacancy & Real wage & Unemployment & Vacancy & Real wage \\
\hline Technology & 0.28 & 0.33 & 0.52 & 0.71 & 0.75 & 1.43 \\
Monetary & 0.26 & 0.30 & 0.69 & 0.83 & 0.82 & 1.41 \\
Financial & 2.24 & 2.17 & 3.61 & 32.8 & 31.4 & 69.8 \\
Investment & 5.81 & 5.69 & 90.34 & 7.02 & 6.67 & 7.48 \\
Preference & 0.77 & 0.73 & 0.31 & 10.9 & 10.3 & 7.56 \\
Government & 0.25 & 0.24 & 0.10 & 1.40 & 1.32 & 0.98 \\
Bargaining & 90.16 & 90.06 & 3.24 & 43.4 & 44.4 & 5.35 \\
Markup & 0.23 & 0.49 & 0.49 & 2.91 & 4.29 & 5.98 \\
\hline
\end{tabular}


is the financial shock. I find that the value of $\chi$ depends on whether the financial data are included in the estimation. Once the financial data are included in the estimation, $\chi$ is estimated at a much larger value than what the literature usually considers. Several exercises conducted in the paper suggest that this result is robust.

More work is necessary, however, to ensure a robust identification of the key labour market parameters. For example, the estimate of the degree of wage rigidity is quite different from the one the micro data suggest. Another line of future research is to incorporate financial frictions that explicitly affect firms' hiring decisions into a monetary DSGE model. As the existing literature has already shown, firms' hiring activities can be directly related to how easily the firms are able to access external funds. It would be interesting to evaluate the impact of this type of financial frictions on unemployment and vacancies at the aggregate level. 


\section{Appendix}

\subsection{Appendix A: System of Equations}

$$
\begin{aligned}
& \lambda_{t}=\frac{e_{t}}{c_{t}-h c_{t-1}}-\beta h E_{t}\left[\frac{e_{t+1}}{c_{t+1}-h c_{t}}\right], \\
& \lambda_{t}=r_{t}^{n} \beta E_{t}\left[\frac{\lambda_{t+1} p_{t}}{p_{t+1}}\right] \\
& E_{t} r_{t+1}^{k}=\frac{E_{t}\left[p_{t+1}^{w} \alpha \frac{y_{t+1}}{k_{t+1}}+q_{t+1}(1-\delta)\right]}{q_{t}} \\
& E_{t} r_{t+1}^{k}=E_{t} \frac{r_{t}^{n} s_{t}}{1+\pi_{t+1}} \\
& N_{t+1}=\eta^{e} \gamma_{t}\left[r_{t}^{k} q_{t-1} k_{t}-\frac{r_{t-1}^{n} s_{t-1}}{1+\pi_{t}}\left(q_{t-1} k_{t}-N_{t}\right)\right] \\
& s_{t}=\left(\frac{q_{t} k_{t+1}}{N_{t+1}}\right)^{\chi} \\
& k_{t+1}=(1-\delta) k_{t}+\tau_{t} i_{t} \\
& q_{t} \tau_{t}=1+\xi\left(\frac{i_{t}}{k_{t}}-\delta\right) \\
& m_{t}=\sigma_{m} u_{t}^{\sigma} v_{t}^{1-\sigma} \\
& n_{t+1}=\rho n_{t}+m_{t} \mu_{t} \\
& u_{t}=1-n_{t} \\
& x_{t}=\frac{q_{t}^{l} v_{t}}{n_{t}} \\
& \kappa x_{t}^{*}=\beta E_{t} \Lambda_{t, t+1}\left[p_{t+1}^{l} a-w_{t+1}^{*}+\frac{\kappa}{2} x_{t+1}^{* 2}+\rho \kappa x_{t+1}^{*}\right] \\
& w_{t}^{f l e x}=\eta_{t}\left(p_{t}^{l}+\frac{\kappa}{2} x_{t}^{2}+\kappa s_{t+1}^{l} x_{t}\right)+\left(1-\eta_{t}\right) \bar{b} \\
& w_{t}^{t a r}=w_{t}^{f l e x}+\eta_{t}\left[\frac{\kappa}{2}\left(x_{t}^{* 2}-x_{t}^{2}\right)+\kappa s_{t+1}^{l}\left(x_{t}^{*}-x_{t}\right)\right] \\
& +\left(1-\eta_{t}\right) s_{t+1}^{l} \beta \Lambda_{t, t+1} \lambda \pi \frac{p_{t}}{p_{t+1}} \Delta_{t+1}\left(w_{t}-w_{t}^{*}\right) \\
& \Delta_{t} w_{t}^{*}=w_{t}^{t a r}(i)+\lambda \rho \beta E_{t} \Lambda_{t, t+1} \Delta_{t+1} w_{t+1}^{*} \\
& \Delta_{t}=1+E_{t} \Lambda_{t, t+1}(\rho \lambda \beta) \frac{p_{t}}{p_{t+1}} \pi \Delta_{t+1} \\
& w_{t}^{n}=(1-\lambda) w_{t}^{n *}+\lambda \pi w_{t-1}^{n} \\
& p_{t}^{w}(1-\alpha) \frac{y_{t}}{l_{t}}=p_{t}^{l}
\end{aligned}
$$




$$
\begin{gathered}
y_{t}=c_{t}+c_{t}^{e}+i_{t}+g_{t}+\frac{\kappa}{2} x_{t}^{2} n_{t}+\frac{\xi}{2}\left(\frac{i_{t}}{k_{t}}-\delta\right)^{2} k_{t} \\
y_{t}=z_{t} k_{t}^{\alpha} l_{t}^{1-\alpha} \\
p_{t}^{*}=\left(\frac{\varepsilon}{\varepsilon-1}\right) \frac{E_{t} \sum_{i=0}^{\infty} \nu^{i} \Delta_{i, t+i} m c_{t+1} y_{t+i}\left(\frac{1}{p_{t+i}}\right)^{-\varepsilon}}{E_{t} \sum_{i=0}^{\infty} \nu^{i} \Delta_{i, t+i} y_{t+i}\left(\frac{1}{p_{t+i}}\right)^{1-\varepsilon}} \\
p_{t}=\left[\nu p_{t-1}^{1-\varepsilon}+(1-\nu)\left(p_{t}^{*}\right)^{1-\varepsilon}\right]^{\frac{1}{1-\varepsilon}} . \\
\frac{r_{t}^{n}}{r^{n}}=\left(\frac{r_{t-1}^{n}}{r^{n}}\right)^{\rho_{r}}\left(\left(\frac{\pi_{t}}{\pi}\right)^{\rho_{\pi}}\left(\frac{y_{t}}{y}\right)^{\rho_{y}}\right)^{1-\rho_{r}} e^{\epsilon_{t}^{m}},
\end{gathered}
$$

\subsection{Appendix B: Log-linearized System of Equations}

$$
\begin{aligned}
& \hat{\lambda}_{t}=\hat{r}_{t}+\hat{\lambda}_{t+1}-E_{t} \hat{\pi}_{t+1} \\
& (1-h)(1-\beta h) \hat{\lambda}_{t}=h \hat{c}_{t-1}-\left(1+\beta h^{2}\right) \hat{c}_{t}+\beta h \hat{c}_{t+1}+(1-h)\left(\hat{e}_{t}-\beta h \hat{e}_{t+1}\right) \\
& E_{t} \hat{R}_{t+1}^{k}=\frac{m c \alpha \frac{y}{k}}{m c \alpha \frac{y}{k}+q(1-\delta)}\left(m \hat{c}_{t+1}+\hat{y}_{t+1}-\hat{k}_{t+1}\right)+\frac{(1-\delta)}{m c \alpha \frac{y}{k}+q(1-\delta)} \hat{q}_{t+1}-\hat{q}_{t} \\
& E_{t} \hat{R}_{t+1}^{k}=\hat{r}_{t}+\hat{s}_{t}-E_{t} \hat{\pi}_{t+1} \\
& \hat{n} w_{t+1}=\frac{k}{n w} \hat{R}_{t}^{k}-\left(\frac{k}{n w}-1\right)\left(\hat{r}_{t-1}+\hat{s}_{t-1}-\hat{\pi}_{t}\right)+n \hat{w}_{t}+\hat{\gamma}_{t} \\
& \hat{s}_{t}=\chi\left(\hat{q}_{t}+\hat{k}_{t+1}-\hat{n} w_{t+1}\right) \\
& \hat{k}_{t+1}=(1-\delta) \hat{k}_{t}+\delta \hat{\imath}_{t}+\delta \hat{\tau}_{t} \\
& \hat{q}_{t}=\xi \delta\left(\hat{\imath}_{t}-\hat{k}_{t}\right)-\hat{\tau}_{t} \\
& \hat{m}_{t}=\hat{\sigma} \hat{u}_{t}+(1-\sigma) \hat{v}_{t} \\
& \hat{n}_{t+1}=\rho \hat{n}_{t}+(1-\rho)\left(\hat{m}_{t}+\hat{\mu}_{t}\right) \\
& \hat{u}_{t}=-\frac{n}{u} \hat{n}_{t} \\
& \hat{x}_{t}=\hat{q}_{t}^{l}+\hat{v}_{t}-\hat{n}_{t} \\
& \hat{q}_{t}^{l}=\hat{m}_{t}-\hat{v}_{t} \\
& \hat{s}_{t}^{l}=\hat{m}_{t}-\hat{u}_{t} \\
& \hat{x}_{t}=E_{t} \hat{\Lambda}_{t, t+1}+\left(\frac{\beta}{\kappa x}\right)\left(p E_{t} \hat{p}_{t+1}^{l}-w E_{t} \hat{w}_{t+1}\right)+\beta(x+\rho) E_{t} \hat{x}_{t+1} \\
& \hat{w}_{t}^{f l e x}=\frac{\eta p^{l}}{w} \hat{p}_{t}^{l}+\frac{\eta \kappa x(x+s)}{w} \hat{x}_{t}+\frac{\eta \kappa x s}{w} \hat{s}_{t}^{l}+\left(1-\frac{\bar{b}}{w}\right) \hat{\omega}_{t} \\
& \hat{w}_{t}^{\text {tar }}=\hat{w}_{t}^{\text {flex }}+\left(\tau_{1}+\tau_{2}\right)\left(\hat{w}_{t}-\hat{w}_{t}^{*}\right) \\
& \hat{w}_{t}^{*}=(1-\rho \beta \lambda) \hat{w}_{t}^{f l e x}+\rho \beta \lambda E_{t} \hat{w}_{t+1}^{*}+(1-\rho \beta \lambda)\left(\tau_{1}+\tau_{2}\right)\left(\hat{w}_{t}-\hat{w}_{t}^{*}\right)+\frac{\rho \beta \lambda}{1-\rho \beta \lambda} E_{t} \hat{\pi}_{t+1}
\end{aligned}
$$


where $\tau_{1}=\eta\left(x+s^{l}\right) \lambda \beta \frac{1}{1-(x+\rho) \lambda \beta}$ and $\tau_{2}=(1-\eta) s^{l} \beta \frac{\lambda}{1-\rho \beta \lambda}$

$$
\begin{gathered}
\hat{w}_{t}=(1-\lambda) \hat{w}_{t}^{*}+\lambda\left(\hat{w}_{t-1}-\hat{\pi}_{t}\right) \\
\hat{p}_{t}^{l}=m \hat{c}_{t}+\hat{y}_{t}-\hat{l}_{t} \\
\hat{y}_{t}=\frac{c}{y} \hat{c}_{t}+\frac{i}{y} \hat{\imath}_{t}+\frac{g}{y} \hat{g}_{t}+\frac{\kappa x^{2} n}{y}\left(\hat{x}_{t}+\frac{\hat{n}_{t}}{2}\right) \\
\hat{y}_{t}=\hat{z}_{t}+\alpha \hat{k}_{t}+(1-\alpha) \hat{l}_{t} \\
\hat{r}_{t}^{n}=\rho_{r} \hat{r}_{t-1}^{n}+\left(1-\rho_{r}\right)\left(\rho_{\pi} \hat{\pi}_{t}+\rho_{y} \hat{y}_{t}\right)+\hat{\epsilon}_{t}^{m}
\end{gathered}
$$

\subsection{Appendix C: Steady-state Calculations}

$$
\begin{aligned}
& \pi=1 \\
& m c=\frac{\epsilon-1}{\epsilon} \\
& r^{n}=\frac{\pi}{\beta} \\
& r^{k}=\frac{1}{\eta^{e}} \\
& s=\frac{r^{k}}{r^{n} / \pi} \\
& q=1 \\
& i=\delta k \\
& \frac{y}{k}=\frac{r^{k}-(1-\delta)}{\alpha m c} \\
& \frac{l}{k}=\left(\frac{y}{k}\right)^{-(1 / 1-\alpha)} \\
& \frac{y}{l}=\frac{y}{k} / \frac{l}{k} \\
& p^{l}=(1-\alpha) m c \frac{y}{l} \\
& n=\frac{s^{l}}{1-\rho+s^{l}} \\
& u=1-n \\
& x=s^{l} u / n \\
& x(i)=x \\
& m=s^{l} u
\end{aligned}
$$




$$
\begin{gathered}
v=\frac{m}{q^{l}} \\
\sigma^{m}=\frac{m}{u^{\sigma} v^{1-\sigma}}
\end{gathered}
$$

$\kappa$ and $w$ are solved from the following two steady-state conditions

$$
\begin{gathered}
\kappa x=\beta\left(p^{l}-w+\frac{\kappa}{2} x^{2}+\rho \kappa x\right) \\
w=\eta\left(p^{l}+\frac{\kappa}{2} x^{2}+s^{l} \kappa x\right)+(1-\eta) \bar{b}
\end{gathered}
$$

where

$$
\begin{gathered}
\tilde{b}=\bar{b} /\left(p^{l}+\frac{\kappa}{2} x^{2}\right) \\
w^{f l e x}=w^{t a r}=w^{*}=w \\
l=n \\
y=\frac{y}{l} l \\
k=l /(l / k) \\
N=k(N / k) \\
i=(i / k) k \\
c=y-i-\left(\frac{\kappa}{2}\right) x^{2} n \\
\lambda=1 / c \\
X=\frac{\lambda m c y}{1-\nu_{p} \beta \pi^{\epsilon}} \\
Y=\frac{\lambda y}{1-\nu_{p} \beta \pi^{\epsilon-1}} \\
p^{*}=\left(\frac{1-\nu_{p} p^{\epsilon-1}}{1-\nu_{p}}\right)^{1 /(1-\epsilon)}
\end{gathered}
$$




\section{References}

[1] Acemoglu, D., 2001. “Credit Market Imperpections and Persistent Unemployment," European Economic Review 45, 665-679

[2] Andolfatto, D. 1996. "Business Cycles and Labor Market Search," American Economic Review $86,112-132$

[3] Barattieri, A., S. Basu and P. Gottschalk. 2010. "Some Evidence on the Importance of Sticky Wages," NBER working paper 16130

[4] Barro, R. 1977. "Long-Term Contracting, Sticky Prices and Monetary Policy," Journal of Monetary Economics, 3(3), 305-16

[5] Bernanke, B., M. Gertler and S. Gilchrist. 1999. "The Financial Accelerator in a Quantitative Business Cycle Framework," Handbook of Macroeconomics, 1341-93

[6] Bernanke, B. and M, Gertler. 2000. "Monetary Policy and Asset Price Volatility,” NBER Working paper No. 7559

[7] Calvo, Guillermo. 1983, "Staggered Prices in a Utility Maximizing Framework," Journal of Monetary Economics, 12:383-98

[8] Christensen, Ian and Ali, Dib. 2008. "The Financial Accelerator in an Estimated New Keynesian Model," Review of Economic Dynamics 11, 155-178

[9] Christiano, L.J., M. Eichenbaum, and C.L. Evans. 2005. "Nominal Rigidities and the Dynamic Effects of a Shock to Monetary Policy." Journal of Political Economy113: 1-79.

[10] Christiano, L., M. Trabandt, and K. Waletin. 2011. "Introducing Financial Frictions and Unemployment into a Small Open Economy Model ,"Journal of Economic Dynamics and Control, 35 (2011), 1999-2041

[11] Christiano, L., R. Motto, and M. Rostagno. 2010. "Financial Factors in Economic Fluctuations.” Working Paper Series 1192, European Central Bank.

[12] Christiano, L., M. Eichenbaum, and C., Evans. 2005. "Nominal Rigidities and the Dynamic Effects of a Shock to Monetary Policy," Journal of Political Economy, 113(1): 1-45

[13] De Graeve, Ferre. 2008. "The External Finance Premium and the Macroeconomy: US postWWII Evidence," Journal of Economic Dynamics and Control 32, 3415-40

[14] Den Haan, Wouter J, Garey Ramey, and Joel Watson. 2000. "Job Destruction and Propagation of Shocks." American Economic Review, Vol. 90, pp. 482-98 
[15] Erceg C.J., D.W. Henderson, and A. Levin. 2000. "Optimal Monetary Policy With Staggered Wage and Price Contracts." Journal of Monetary Economics 46(2): 281-313.

[16] Fujita, S. and G. Ramey. 2012. "Exogenous VS. Endogenous Separation,” American Economic Journal: Macroeconomics, forthcoming.

[17] Gertler, M., and A. Trigari. 2009. "Unemployment Fluctuations with Staggered Nash Wage Bargaining," Journal of Political Economy, Vol. 117, No. 1, pp. 38-86

[18] Gertler, M., L. Sala and A. Trigari. 2008. "An Estimated Monetary DSGE Model with Unemployment and Staggered Nominal Wage Bargaining "Journal of Money, Credit and Banking, Vol. 40, No.8, 1714-64

[19] Hagedorn, Macus, and Iourri Manovskii. 2008. "The Cyclical Behavior of Equilibrium Unemployment and Vacancies Revisited.” American Economic Review 98(4), 1692-1706

[20] Hall, Robert. 2008. "Sources and Mechanisms of Cyclical Fluctuations in the Labour Market," Mimeo, Stanford University

[21] Jermann, U. and V. Quadrini. 2012. "Macroeconomic Effects of Financial Shocks," American Economic Review 102(1), 238-271

[22] Merz, M. 1995. "Search in the Labor Market and the Real Business Cycles," Journal of Monetary Economics 36, 269-300

[23] Monacelli, T., Quadrini V., and A., Trigari. 2011. "Financial Markets and Unemployment," NBER Working Paper No. 17389

[24] Petrosky-Nadeau, N. 2009. "Credit, Vacancies and Unemployment Fluctuations," Review of Economic Dynamics, 17(2), 191-205

[25] Queijo von Heideken, V. 2009, "How Important are Financial Frictions in the United States and the Euro Area?," Scandinavian Journal of Economics, Vol 111(3), 567-96

[26] Shimer, R. 2005. "The Cyclical Behavior of Equilibrium Unemployment, Vacancies, and Wages: Evidence and Theory," American Economic Review 95(1), 25-49

[27] Smets, F and R. Wouters. 2007. "Shocks and Frictions in US Business Cycles: A Bayesian DSGE Approach," American Economic Review97(3), 586-606

[28] Wasmer, E. and P. Weil. 2004. "The Macroeconomics of Labor and Credit Market Imperfections," American Economic Review 94(4), 944-963 
Figure 1: Historical Decomposition of Unemployment, 1984Q1-2008Q4

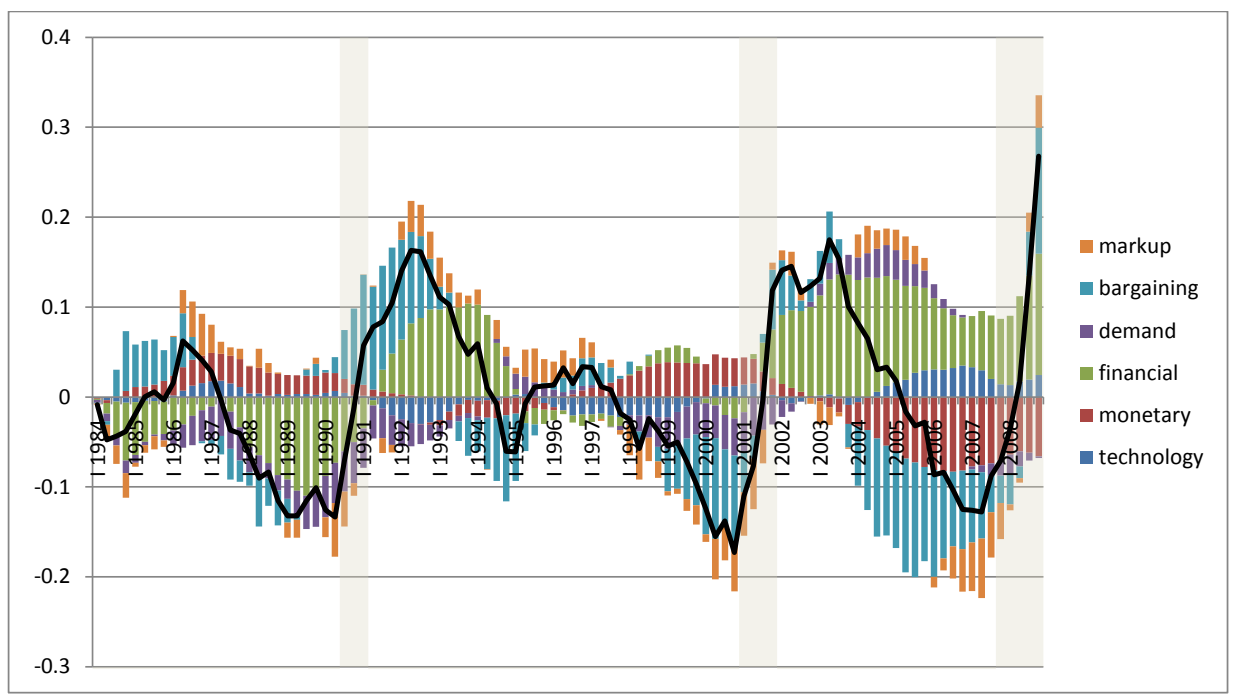


Figure 2: Effects of Financial Accelerator Mechanism
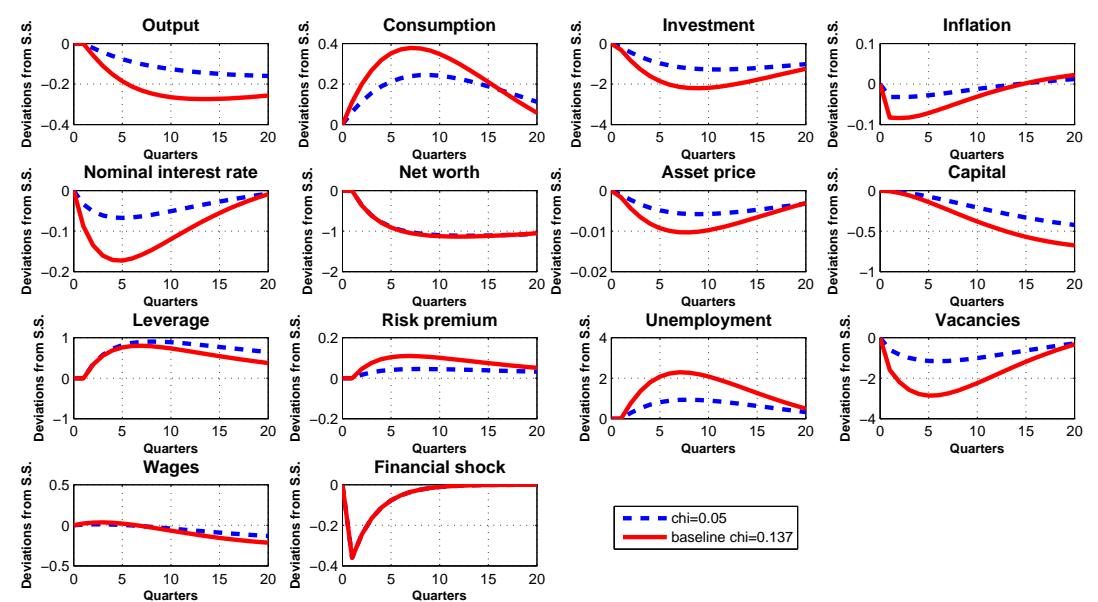

\begin{tabular}{ll}
\hline - - chi 0.05 \\
baseline chi $=0.137$
\end{tabular}

Figure 3: Effects of the Staggered Wage Contracting
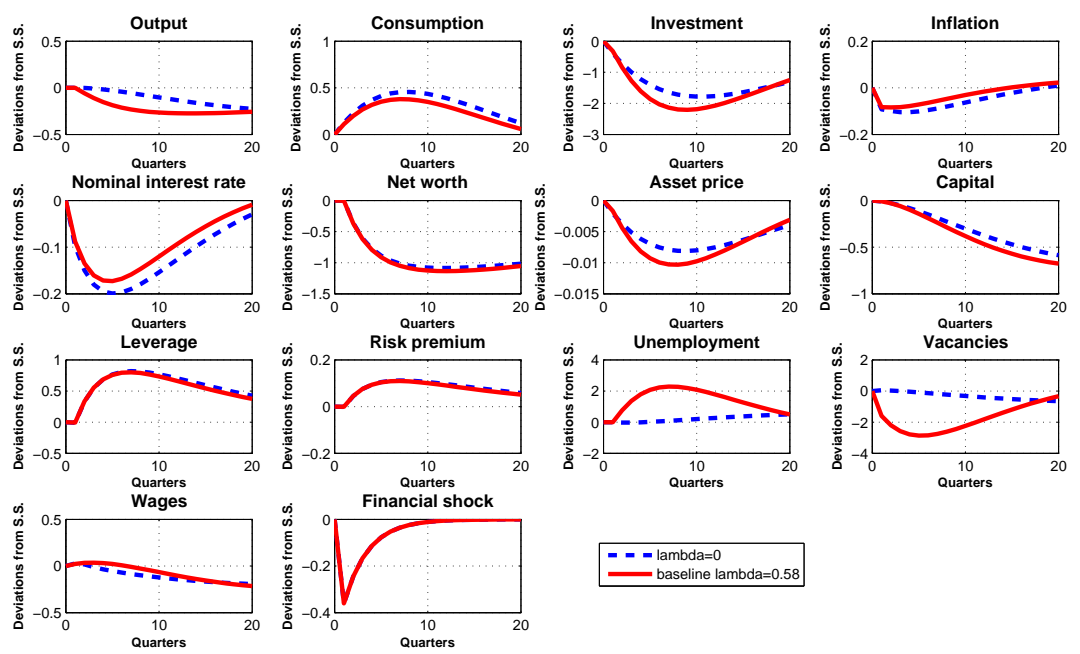

$\begin{array}{ll}\text { - - } & \text { lambda }=0 \\ & \text { baseline lambda }=0.58\end{array}$
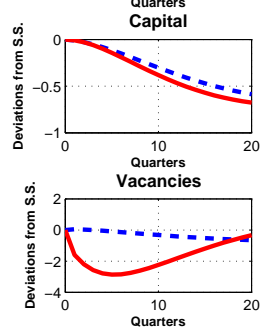